\title{
Effects of pain and fear stimulus intensity levels on pain responding in chronic pain patients
}

\author{
John Thomas Sorrell \\ West Virginia University
}

Follow this and additional works at: https://researchrepository.wvu.edu/etd

\section{Recommended Citation}

Sorrell, John Thomas, "Effects of pain and fear stimulus intensity levels on pain responding in chronic pain patients" (2000). Graduate Theses, Dissertations, and Problem Reports. 755.

https://researchrepository.wvu.edu/etd/755

This Thesis is protected by copyright and/or related rights. It has been brought to you by the The Research Repository @WVU with permission from the rights-holder(s). You are free to use this Thesis in any way that is permitted by the copyright and related rights legislation that applies to your use. For other uses you must obtain permission from the rights-holder(s) directly, unless additional rights are indicated by a Creative Commons license in the record and/ or on the work itself. This Thesis has been accepted for inclusion in WVU Graduate Theses, Dissertations, and Problem Reports collection by an authorized administrator of The Research Repository @ WVU. For more information, please contact researchrepository@mail.wvu.edu. 
Effects of Pain and Fear Stimulus Intensity Levels on Pain Responding

in Chronic Pain Patients

\author{
John T. Sorrell \\ Thesis submitted to the \\ Eberly College of Arts and Sciences \\ at West Virginia University \\ in partial fulfillment of the requirements \\ for the degree of
}
Masters of Arts
in
Psychology
Daniel W. McNeil, Ph.D., Chair
Georg H. Eifert, Ph.D.
Jeannie A. Sperry, Ph.D.
Department of Psychology

Morgantown, West Virginia

2000

Keywords: Clinical Psychology, Human Participants, Pain Challenge, Psychophysiology

Copyright 2000 John T. Sorrell 


\author{
ABSTRACT \\ Effects of Pain and Fear Stimulus Intensity Levels on Pain Responding \\ in Chronic Pain Patients
}

Fear has been found to increase and decrease pain responding in various contexts, and the effects of fear and pain stimulus intensity levels on pain responding have not been examined. Forty chronic pain patients were exposed to an algometer pressure pain device which stimulated different fingers; there were two levels of pressure pain (i.e., high and low). Also, there were two levels of induced fear (i.e., high and low). Significant main effects of pain stimulus intensity level were found on threshold pain time, tolerance pain time, and self-reports of fear and pain. Also, a significant main effect of gender was found on tolerance pain time. Pain and fear levels interacted for heart rate; significant increases in heart rate occurred only in the combined high pain and high fear condition. Sensitivity to pain stimulus intensity, the effects of stimulus intensity on gender, and the additive effects of high fear and pain are discussed. 


\section{Acknowledgments}

I first would like to thank my thesis committee, Dr. Georg H. Eifert and Dr. Jeannie A. Sperry, for their positive feedback and support of this ambitious project. To my thesis committee chair, colleague, and dear friend, Daniel W. McNeil, I express my deepest thanks. Without the continuous support, encouragement, and reassurance received from Dan, I certainly would not have survived the many challenges that I have faced during the past two and a half years.

Kevin E. Vowles and Shannon G. Kennedy were invaluable in providing assistance throughout the course of my thesis, particularly during the data collection phase. Their hard work, dedication, and tremendous enthusiasm helped make the "grunt work" manageable and fun.

My closest friends, Carl W. Lejuez and Nicholas A. Macri, have been supportive throughout this project, and their own talents and accomplishments truly have been inspiring. These individuals have displayed acts of unparalleled friendship towards me that I will forever cherish.

To my three brothers Robert, Joseph, and Vincent, thank you for all the encouragement and support you have given me throughout my life. Without you, I would not be where I am today and could not have survived our shared hardships. To Denise and Sheri, I always will treasure the special support you have given me as sisters. And Madison, you have opened my eyes to once unimaginable wonders.

I cannot express in words the amount of thanks and appreciation I feel for all that my loving parents, Robert and Catherine, have provided me. As I think back to when I was a young child and followed my father's footsteps in the sand at the beach, I would give anything to let him see what his love and inspiration has helped me accomplish. Likewise, my mother's unconditional love, devotion, and relentless support throughout my life has carried me further than I ever dreamed.

I also would like to thank West Virginia University's Department of Anesthesiology and Department of Psychology Alumni Fund for financial support of this research, and everyone at the West Virginia Pain Treatment Center for their friendly assistance in conducting this investigation. 


\section{Table of Contents}

Title Page

Abstract

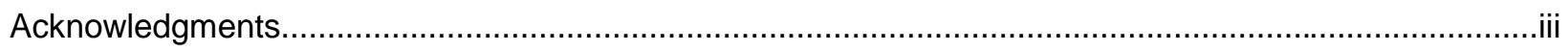

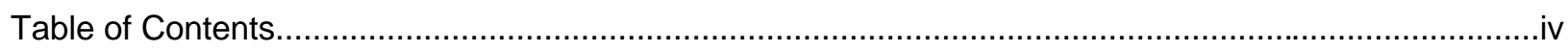

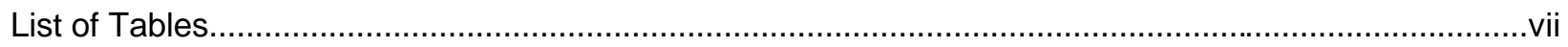

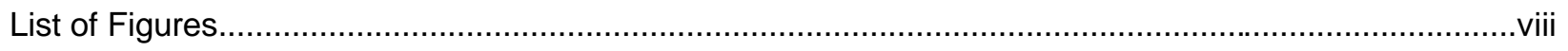

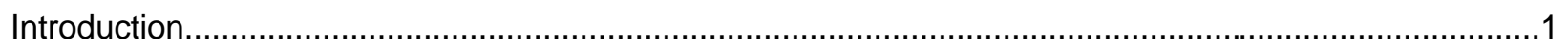

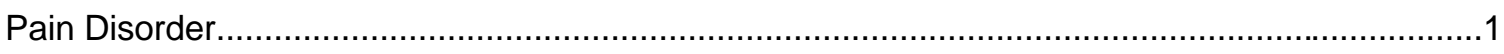

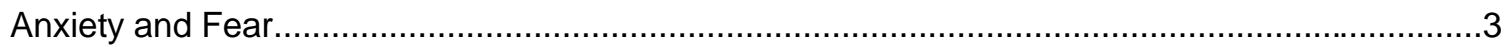

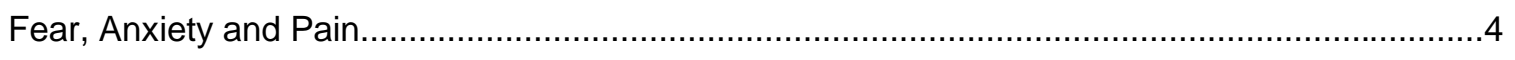

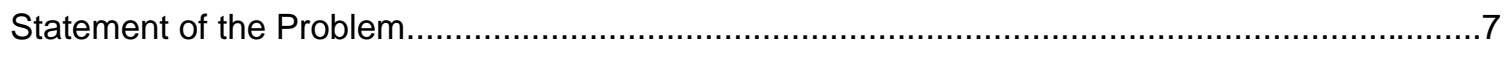

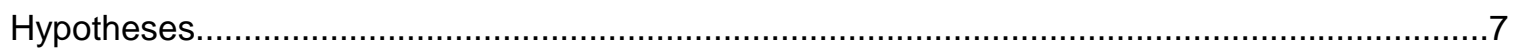

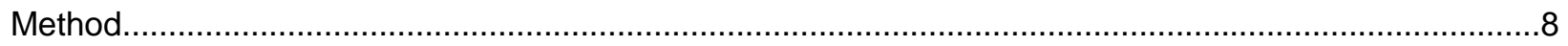

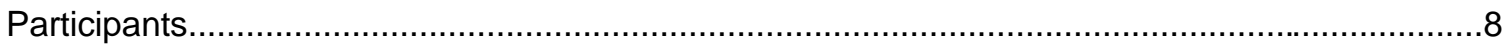

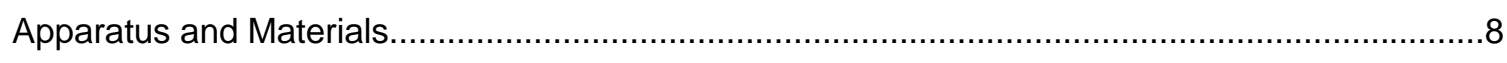

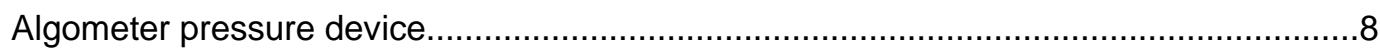

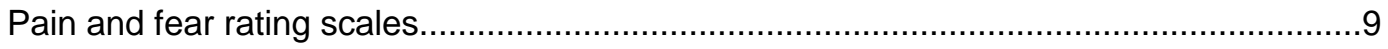

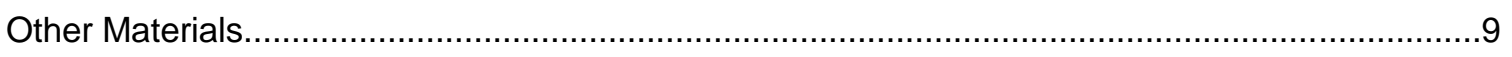

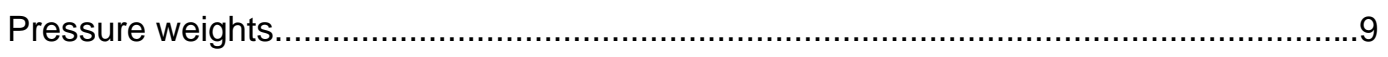

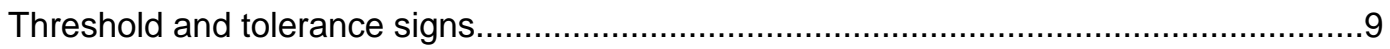

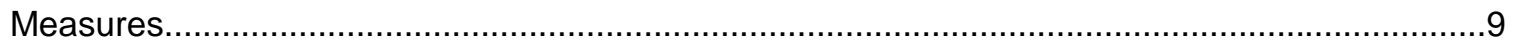

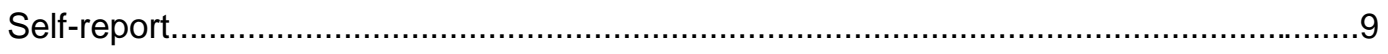

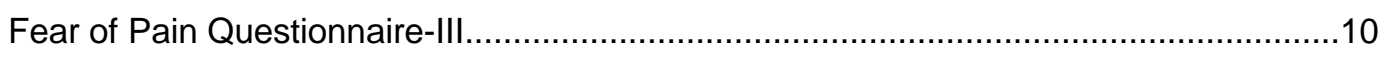

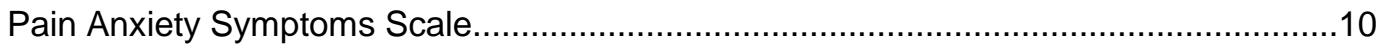

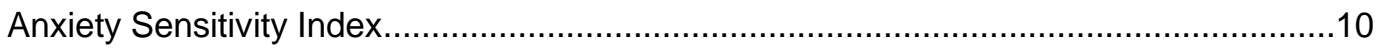

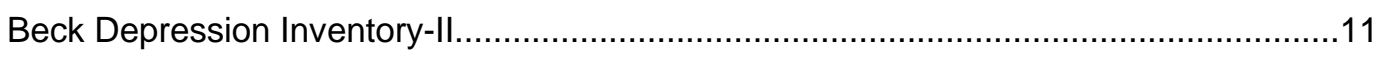




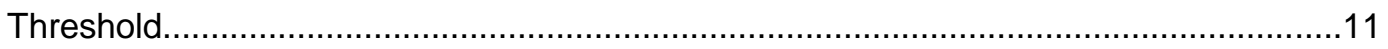

Tolerance

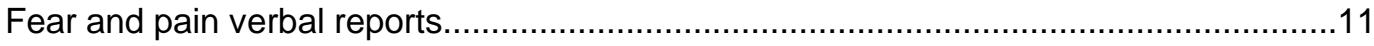

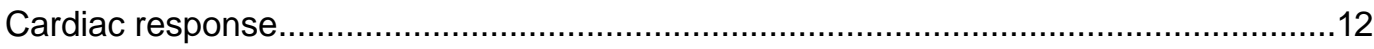

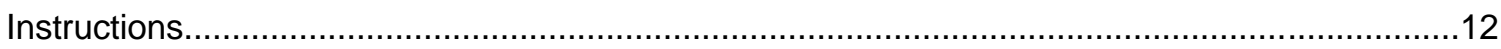

Procedure

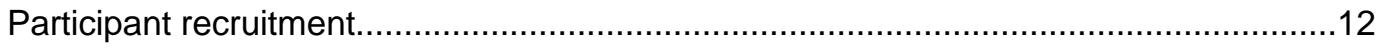

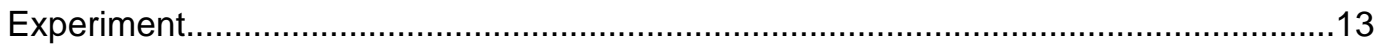

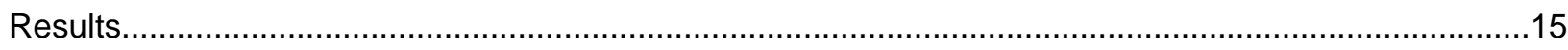

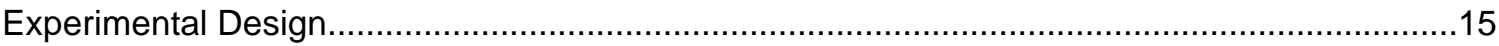

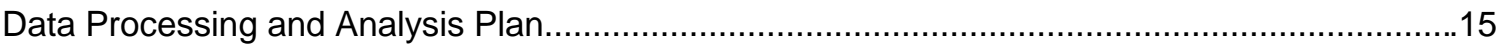

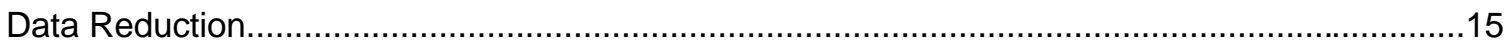

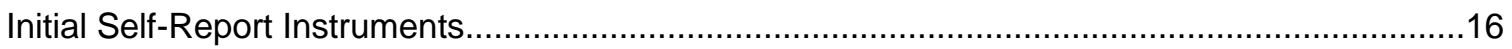

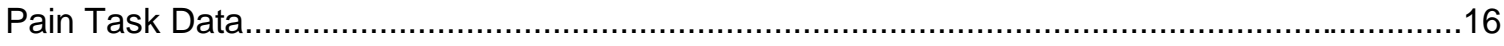

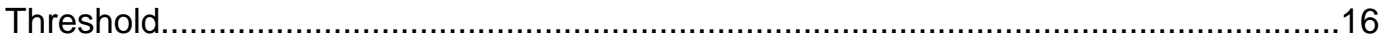

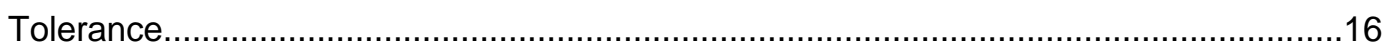

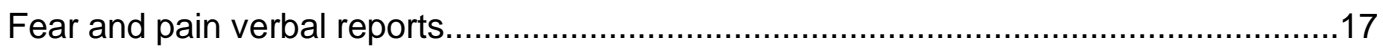

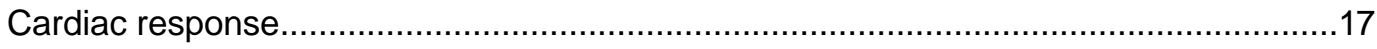

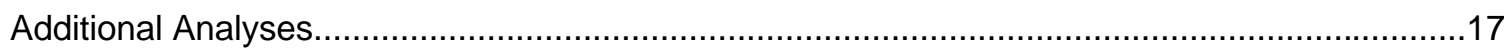

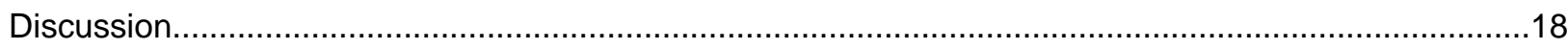

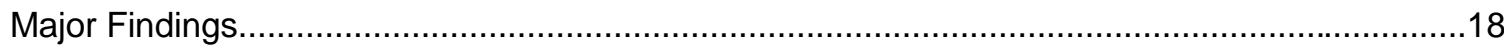

Pain responding sensitive to pain and fear stimulus intensity....................................18

Unpredicted effect of stimulus intensity on gender.................................................19

Additive effects of high fear and high pain..........................................................19

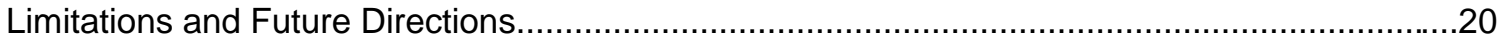

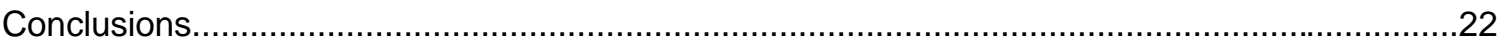

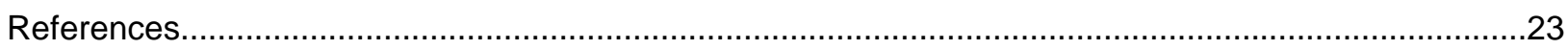




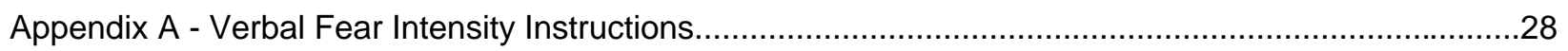

Appendix B - Patient Telephone Contact/Recruitment Protocol.......................................................29

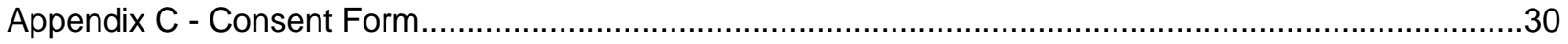

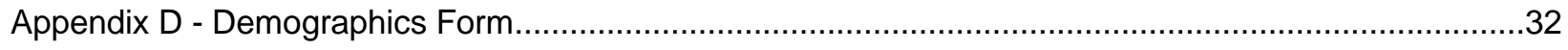

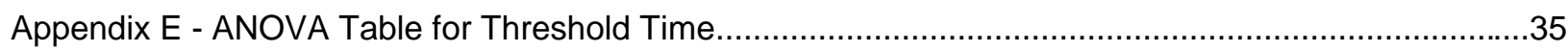

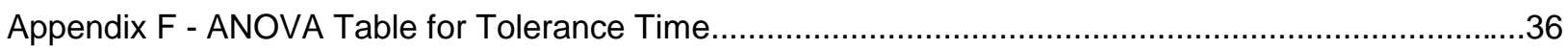

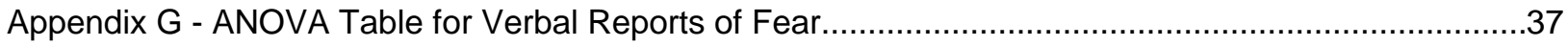

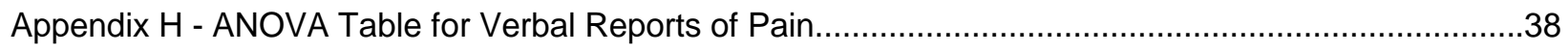

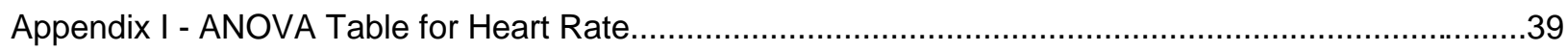

Appendix J - ANOVA Table for Threshold Time (Between Subjects) ..................................................40

Appendix K - ANOVA Table for Tolerance Time (Between Subjects)................................................41

Appendix L - ANOVA Table for Verbal Reports of Fear (Between Subjects)......................................42

Appendix M - ANOVA Table for Verbal Reports of Pain (Between Subjects).......................................43

Appendix N - ANOVA Table for Heart Rate (Between Subjects) .......................................................44

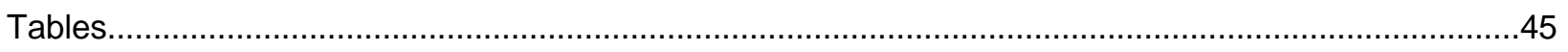

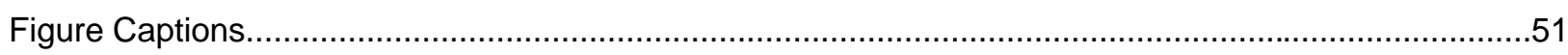

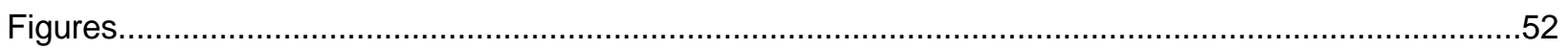

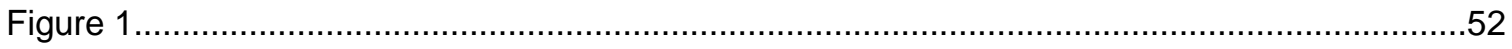

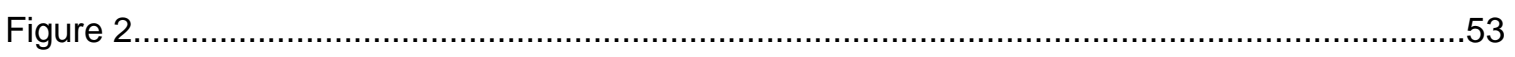

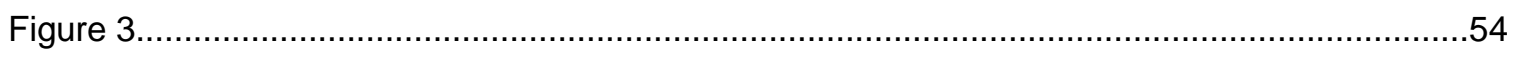

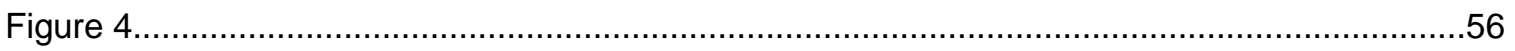

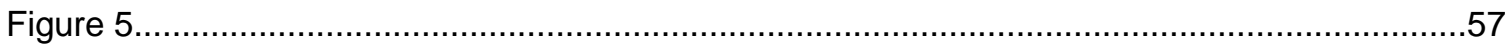

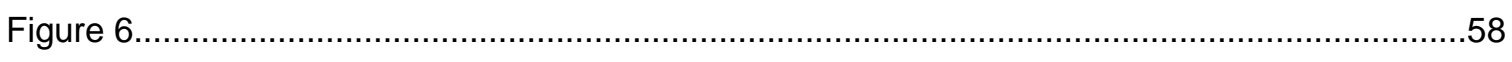

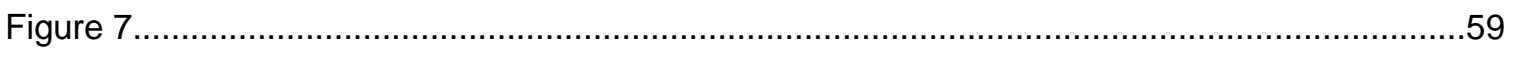

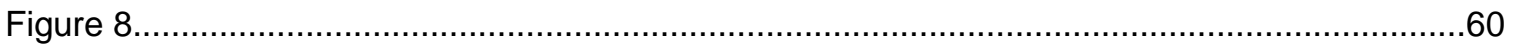

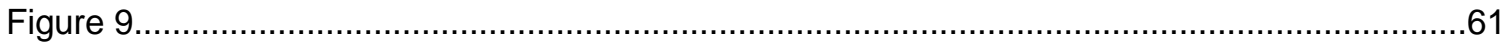




\section{List of Tables}

1. Pain locations and total number and percent of participants with that chronic pain site....................45

2. Medications used by participants as part of their treatment at the pain treatment center...................46

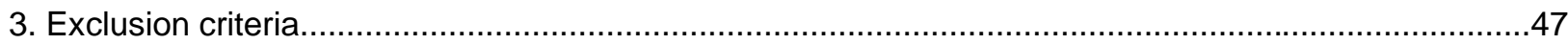

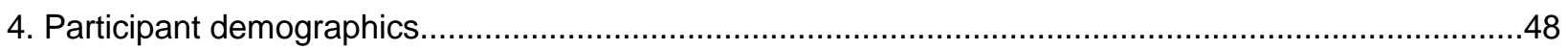

5. Mean and standard deviation values for all three modes of responding by condition........................49

6. Means and standard deviations for the four self-report measures: FPQ-III, PASS, ASI, and BDI-II.....50 


\section{List of Figures}

1. Number Rating Scales (NRS) used by participants for verbal reports of fear and pain.

2. "Painful" and "Stop Stimulation" signs used by participants to indicate when the pressure stimulation became painful (i.e., threshold) and/or to stop the condition (i.e., tolerance), respectively......

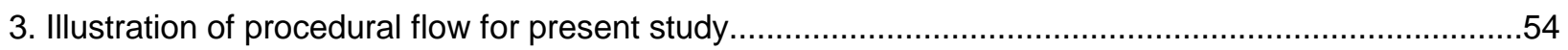

4. Mean threshold times (s) for all participants in each condition......................................................56

5. Mean tolerance times for all participants in each condition..........................................................57

6. Mean tolerance times for male and female participants across each condition................................58

7. Mean fear change ratings for all participants in each condition...................................................59

8. Mean pain change ratings for all participants in each condition.....................................................60

9. Mean heart rate change scores for all participants in each condition.............................................61 
Stimulus Intensity, Pain, and Fear 1

\section{Effects of Pain and Fear Stimulus Intensity Levels on Pain Responding \\ in Chronic Pain Patients}

The negative effects of chronic pain problems are numerous, particularly as affected individuals often unsuccessfully struggle to maintain personal, social, health, and occupational functioning (Tollison, Kriegel, \& Downie, 1985). It has been shown, for example, that affective disorders such as depression are frequent in chronic pain patients (Polatin, 1991) and the financial cost to the individual and society are quite burdensome. Enormous amount of time, money, and research efforts have been made to better understand the dynamics of pain problems, and particularly chronic pain. One area that has received focus in understanding pain responding are the effects of fear, anxiety, and attention on pain responding (Arntz \& De Jong, 1993; Arntz, Dreessen, \& De Jong, 1994; Arntz, Dreessen, \& Merckelbach, 1991; Crombez, Eccleston, Baeyens, \& Eelen, 1998; Crombez, Vlaeyen, Heuts, \& Lysens, 1999).

During this time of increased consideration of fear, anxiety, and attention on pain responding, however, there has been a lack of consensus among researchers on exactly how these variables affect the pain experience for humans. Some research suggests, for example, that fear and anxiety increase pain (e.g., Williams, 1996) while other have found that these emotions decrease pain responding (e.g., Al Absi \& Rokke, 1991). More recently, Rhudy and Meagher (2000) found fear to elicit analgesic effects while anxiety elicits hypersensitivity to experimentally induced pain stimulation in humans. Further, although pain stimulus intensity has been mentioned to be a significant variable contributing to the pain experience (Tollison, Hinnant, \& Kriegel, 1991; Weisenberg, 1997), there has yet to be a study to show the effects of pain and fear stimulus intensity levels on pain responding in chronic pain patients. The present study will attempt to show the importance of pain and fear stimulus intensity levels with regard to pain responding in this clinical population. The following sections will briefly review chronic pain disorder, fear, how fear may interact to affect pain problems, and the research that has accumulated regarding these specific focuses on pain responding in humans.

\section{$\underline{\text { Pain Disorder }}$}

Pain disorder is categorized under the broader classification of somatoform disorders in the 
Stimulus Intensity, Pain, and Fear 2 Diagnostic and Statistical Manual of Mental Disorders, fourth edition (DSM-IV; American Psychiatric Association [APA], 1994). Included with pain disorder in the somatoform classification are somatization disorder, undifferentiated somatoform disorder, conversion disorder, hypochondriasis, and body dysmorphic disorder (see Eifert, Lejuez, \& Bouman, 1998 for a review). According to Eifert et al. (1998), pain disorder is not easily understood, nor can it be fully accounted for by a known medical condition. Further, pain is a phenomenon in which psychological factors such as mood, anxiety, and attention may be involved in its onset, maintenance, or exacerbation. Despite the difficulty in understanding pain disorder, pain is one of the most common problems that patients present to physicians as well as being a frequently cited cause of disability.

Pain is the primary symptom that leads individuals to seek medical treatment and accounts for over 35 million new office visits to physicians a year in the United States (Turk \& Melzack, 1992). Pain and related dysfunctions result in loss of contribution to the work force, financial strain, medical expenses, and negative effects on family care and cohesiveness. There are many reasons individuals experience pain, including disease, automobile accidents, surgeries, and sports-related injuries. For pain to be considered a psychiatric disorder, however, there must be significant disruption in the functioning of an individual's life. According to the DSM-IV (1994), pain disorder is characterized by acute or chronic pain to one or more body parts that causes significant distress or impairment in social, occupational, or other important areas of functioning, and involves psychological factors in pain onset, severity, exacerbation, or maintenance. Acute pain is characterized as pain of a duration of less than 6 months while chronic pain is of a duration of 6 months or more.

Theoretical accounts developed to better understand and explain pain have focused on biological models (Melzack \& Wall, 1965), behavioral models (Fordyce, Roberts, \& Sternbach, 1968), cognitive models (Eccleston, 1994), and a number of combinations of these perspectives (e.g., Biopsychosocial model; Turk, 1996). The gate control theory (Melzack \& Wall, 1965), for example, was developed to account for the complex interaction of sensory, motivational, and cognitive components that contribute to the pain experience. Unlike primarily behavioral and cognitive models of pain responding that focus on environment-behavior relations (e.g., reinforcement contingencies) and 
Stimulus Intensity, Pain, and Fear 3

information processing/cognitive schema, respectively, gate control theory focuses on the modulation effects of three variables: (a) the A-delta fibers that carry messages of sharp pain, (b) the $C$ fibers that carry messages of dull pain, and (c) A-beta fibers that carry messages of light touch (see Melzack \& Wall, 1982 for a review).

\section{$\underline{\text { Anxiety and Fear }}$}

Similar to pain, the effects of anxiety and fear also can cause significant life disruption in a person's social and occupational spheres. In fact, Barlow (1988) contends, "anxiety disorders represent the single largest mental health problem in the country ... the prevalence rate of anxiety disorders surpasses that of any other mental health disorder" (p. 22). Anxiety has been conceptualized as a mood state characterized by marked negative affect and somatic symptoms of tension in which a person apprehensively anticipates future danger or misfortune (Barlow, 1988). In moderate degrees, anxiety can facilitate one's ability to perform in a given situation; more extreme levels, however, can have a detrimental and crippling effect. When there is an excessive level of anxiety, an individual may lose focus of the task at hand and become debilitated by a focus on the anxiety or fear of an unpleasant, upcoming event.

Although efforts have been made to differentiate anxiety and fear as separate constructs of emotional responding (see Barlow, 1988; Barlow, 1991; McNeil, Turk, \& Reis, 1994; Rhudy \& Meagher, 2000 for a review), there is considerable overlap among these emotions. As McNeil et al. (1994) have suggested, anxiety and fear are multidimensional emotional states (e.g., overt behaviors, physiological responding, and cognitive processes) that often are used interchangeably in everyday language. This fundamental misuse of terms, however, overlooks fear as a fundamental emotional response functioning as an alarm system which physiologically prepares an organism for immediate fight or flight, and also overlooks anxiety as a diffuse feeling of worry and distress (McNeil et al., 1994). Given that these psychological states overlap considerably with regard to physiological, cognitive, and overt responding, and that it is not the primary focus of this manuscript to differentiate fear and anxiety, these terms will be used somewhat interchangeably to indicate psychological preparedness (e.g., fight or flight) for an upcoming aversive event. 
Stimulus Intensity, Pain, and Fear 4

\section{Fear, Anxiety, and Pain}

The multifaceted nature of the relation between fear and pain is due in part to historical and contemporary conceptualizations of these states (Gross \& Collins, 1981). Throughout history, particularly during the times of early philosophers (e.g., Aristotle, Epictetus), theories of pain were unidimensional (Eifert et al., 1998). Not until more recently, however, has there been an emphasis on multidimensional models of pain, both in its conceptualization (e.g., Turk, 1996) and its treatment (e.g., Hadjistavropoulos \& Craig, 1994; Zvolensky, Gross, Sorrell, Boggess, \& Sperry, 2000). Such multidimensional models also exist for anxiety and fear. For example, Barlow (1988) discusses anxiety in terms of a diathesis-stress model, in which one has a biological predisposition or genetic vulnerability to develop an anxiety disorder. Although in some individuals an anxiety disorder may develop in the absence of an environmental stressor, according to this diathesis-stress model it is not until that individual encounters a significantly stressful life event does the disorder emerge. Given these historical and contemporary differences in the conceptualization of pain and fear, there has been considerable focus on how these variables interact in formulating the entire pain experience. With the results of these studies, however, there has been disagreement in how fear affects pain, and vice versa.

Many contend that fear and anxiety will reduce pain threshold, essentially increasing the pain experience (Williams, 1996). Several studies have demonstrated that increasing levels of fear are associated with increased pain reports (e.g., Al Absi \& Rokke, 1991) while others argue against the idea that fear increases pain responding and state that fear decreases pain (e.g., Bolles and Fanselow, 1980). Specifically, Bolles and Fanselow (1980) suggest that fear and pain are exclusive states in which fear has priority over pain; that is, when these states co-occur, pain diminishes as fear increases.

In addition to fear and anxiety, other factors such as happiness and depression have been suggested to increase or decrease, respectively, pain responding (Carter, McNeil, Vowles, Sorrell, Turk, \& Ries, 2000). Furthermore, attentional variables have been the focus of considerable concern in regard to pain responding (e.g. Al Absi \& Rokke, 1991; Arntz, Dreessen, \& Merckelbach, 1991; Arntz \& De Jong, 1993; Arntz, Dreessen, \& De Jong, 1994; Crombez, et al., 1998; Ecclesten, 1994). The effects of attention on pain responding may have been clouded by the exclusive focus of early research on fear as 
Stimulus Intensity, Pain, and Fear 5 the most influential construct contributing to pain responding in humans. Arntz et al. (1991) investigated the influences of anxiety and attention on pain responding and determined that attention, rather than anxiety, influences pain responding. In high versus low anxiety and attention towards versus distraction from painful stimulation conditions, spider phobics' responded to painful electrical stimulation. Anxiety effects were not significant across conditions, but attention was related to stronger skin conductance responses to electrical stimulation and lower subjective pain ratings were reported in the distraction conditions compared to attention conditions. The results from this study suggest that: (a) attention to pain is clearly related to stronger pain responses, (b) anxiety is not related to stronger pain responses, and (c) anxiety is not related to weak pain response.

In an extension to the study by Arntz et al. (1991), Arntz and De Jong (1993) attempted to clarify whether anxiety or attention was more influential in pain responding. Using a single subject design rather than a group design, the conditions and procedure in this study were similar to that used previously by Arntz et al. (1991). Furthermore, the results obtained in this study were congruent with the aforementioned experiment. When attention was controlled for, anxiety purportedly had no influence on subjective and physiological responses to painful electrical stimulation. Also, pain responses were strongly affected by attentional focus, regardless of anxiety level.

In a third study by Arntz et al. (1994), two psychological processes mediating the influence of anxiety on pain were investigated: attributional processes and attentional processes. Specifically, the investigators focused on attentional variables, pain-irrelevant and pain-relevant anxiety in the responsiveness to a painful stimulus in spider phobics. Using similar conditions and procedures as the two previous studies, spider phobics were exposed to a painful electrical stimulus. Results suggest that pain ratings only were influenced by attentional focus and not by anxiety or its pain-relevance.

Contrary to the findings by Arntz et al. (1994), other studies have found that relevant anxiety does affect responses to pain stimuli. Al Absi and Rokke (1991) hypothesized that anxiety that is relevant to the source of pain exacerbates pain, whereas anxiety that is irrelevant to the source of pain reduces the pain response. In this study, subjects were given information to provoke a high or low anxiety response about a cold pressor task (relevant anxiety) or potential shock (irrelevant anxiety). 
Stimulus Intensity, Pain, and Fear 6

Results suggest that irrelevant anxiety produced less of a pain response than relevant anxiety to the cold pressor. According to these results, anxiety has a differential effect on pain responding depending on whether or not it is relevant to the pain.

A possible reason for the discrepancy in results between Al Absi and Rokke (1991) and Arntz et al. (1994) is that Al Absi and Rokke used pain-associated information to evoke anxiety for both the relevant and irrelevant anxiety conditions. The Arntz et al. (1994) procedure did not use pain-related information in the irrelevant anxiety conditions. Furthermore, Arntz et al. (1991) argue that attention is the critical variable in accounting for pain responding, but they do not consider that the pain stimulus maybe of greater intensity relative to the fear or distraction stimulus intensity levels; thus having pain responding dominate other possible behaviors (e.g., fear response) in that situation (cf. Bolles and Fanselow, 1980).

Given this discordance in results between studies, there may be underlying variables that have been overlooked as a contributing factor to pain responding. In particular, one variable that may not have been considered is stimulus intensity, specifically regarding the physical properties of the intensity of a fear or pain stimulus. Physical properties of stimulus intensity refer to the measurable aspects of a stimulus such as weight, length, volume, and/or duration. The properties of pain stimulus intensity, for example, may include the temperature of ice water or the amount of weight used to induce pressure pain. The physical properties of fear stimulus intensity may include the sound frequency and volume of an alarm or the verbal language used to describe an upcoming event (Gaffney, Foenander, Reade, \& Burrows, 1987; Kremer \& Atkinson, 1984; Melzack \& Torgerson, 1971). When stimulus intensity is considered in this regard, the discordance in results from the aforementioned studies may be better explained. Attentional factors may override anxiety variables in contributing to increased pain responses if the attentional stimuli are more intense than both the anxiety and pain stimuli. Thus, the attention stimulus may be a more salient discriminative stimulus and functions to detract from the establishing operation function of pain and fear.

Additionally, if a distractor stimulus is more intense relative to the anxiety and pain stimuli, then it seems likely that the pain response would be less when the distractor stimulus is present. Based on this 
reasoning, a young child experiencing a painful medical procedure may not have as high a pain response if she was able to watch the most intense and exciting cartoon she has ever seen. Furthermore, if the intensity of anxiety-evoking stimuli was higher relative to distractor, pain, and/or attentional stimuli, then responding may be greater in the anxiety condition. So if an intensely anxious student pricks his finger as he plays with a sharp object while waiting to be called on to give his book report, he may not have the same pain response that he would if he was intently focused on his finger or in the dentist's office awaiting a painful root canal.

\section{Statement of Problem}

Although some previous research suggests that attention towards a pain stimulus will increase the pain response, and distraction from the pain stimulus by attending to another stimulus will decrease the pain response (Arntz \& De Jong, 1993), contradictory results have been found (e.g., Al Absi \& Rokke, 1991). Because of this discordance among findings and the lack of evidence documenting stimulus intensity as a relevant variable in producing such results, the present study attempted to determine the effects of fear and pain stimulus intensity on pain responding in humans. This question was investigated using a $2 \times 2$ within subjects experimental design, in which fear and pain stimulus intensity levels were the two independent variables. There was a high and low intensity condition for both fear and pain.

\section{$\underline{\text { Hypotheses }}$}

The following hypotheses were tested: (a) pain responding will be sensitive to pain and fear stimulus intensity levels, such that high stimuli will produce greater levels of responding and lower intensity stimuli will produce lower levels of responding, and (b) additive effects of high pain and high fear together will lead to the greatest pain responding of all. Hypothesis $|a|$ is predicted because fears have been found to summate (Rachman \& Lopatka, 1986). Because pain is in part an emotional response, fear and pain stimulus intensity levels may be additive, producing a greater pain response. When stimulus intensity levels are low, there will be relatively little pressure stimulation or fear to increase vigilance responding (e.g. fight or flight). Hypothesis $|\mathrm{b}|$ is predicted because high pain and fear stimulus intensity levels are likely to function as greater establishing operations relative to low pain and 
fear stimulus intensity levels.

\section{Method}

\section{$\underline{\text { Participants }}$}

Participants were 40 chronic pain outpatients, 20 females and 20 males. They ranged in age from 25 to 61 years $(\underline{M}$ age $=43.3, \underline{S D}=9.5)$. There were $38(95 \%)$ Caucasian and $2(5 \%)$ AfricanAmerican participants; all had a prolonged history of chronic pain between 7 and 444 months $(\underline{M}$ duration of pain chronicity $=103.5$ months, $\underline{\mathrm{SD}}=88.9$ ). See Table 1 for participant's primary chronic pain sites. The marital status of participants consisted of $72.5 \%(\underline{n}=29)$ being married, $12.5 \%(\underline{n}=5)$ separated or divorced, and $15 \%$ as either single $(\underline{n}=4)$, widowed $(\underline{n}=1)$, or having a live-in-partner $(\underline{n}=$ 1). Medications recorded in participant's medical charts at the pain treatment center are reported in Table 2. Preestablished exclusion criteria were used to screen participants to help ensure their safety prior to beginning the procedure. Table 3 displays the exclusion criteria used. Each participant was debriefed and received $\$ 25.00$ following the completion of the procedure.

\section{$\underline{\text { Apparatus and Materials }}$}

Algometer pressure device. Pain stimulation was induced using an algometer pressure pain stimulator similar to that introduced by Forgione and Barber (1971). Modifications made to the algometer were utilized based on experimentation by Dougher, Goldstein, and Leight (1987) and are extensively diagramed by Rainwater and McNeil (1991). The algometer is a device that allows for the placement of a dull lucite blade on the second phalanx to individual fingers of the hand, using weights of different mass. From a vertical slide position, and when pressure weights are in place, the algometer produces a slowly building, aching pain. The middle and ring fingers of each hand were utilized for each participant, in counterbalancing order. Participant's index finger on the opposite hand to be used in the first pain condition also was used for an initial exposer to the device, experimental procedure, and to reduce reaction effects in the first condition. The duration of the pain stimulation for each participant was no longer than five minutes and the participant could terminate the stimulation at anytime. Pain threshold (i.e., the time that stimulation becomes painful), pain tolerance (i.e., the time that stimulation can no longer be endured), and the length of the five minute conditions were monitored and recorded using a 
hand-held stopwatch.

Pain and fear rating scale. The Number Rating Scales (NRS) used to obtain participant's expected pain and fear ratings, as well as their actual pain and fear ratings, are displayed in Figure 1. The pain NRS was green in color and was always placed immediately to the left of the fear NRS, which was pink in color. These rating scales remained on the top edge of the table during each condition so participants could refer to it when asked to give their pain and fear ratings. Between conditions, the rating scales were removed from the table.

Other Materials

Pressure weights. Two large red cylindrical containers, one weighing $500 \mathrm{~g}$ and the other $1000 \mathrm{~g}$, and two small blue cylindrical containers, one weighing $500 \mathrm{~g}$ and the other $1000 \mathrm{~g}$, were used with the algometer to produce two levels of pressure stimulation. In addition, one small tan cylindrical container weighing $750 \mathrm{~g}$ was used for an initial exposure condition to introduce the participant to the experimental procedure and related stimuli. At the start of each pain challenge, one of these weights was placed on top of the algometer to produce the pressure stimulation for that condition. At the end of the 5-min condition, or when the participant chose to discontinue, the weight was removed from the algometer.

Threshold and tolerance signs. Figure 2 displays the "Painful" and "Stop Stimulation" signs used by participants to indicate when the pressure stimulation became painful (i.e., threshold) and/or to stop the condition (i.e., tolerance), respectively. The threshold sign was the same shape (i.e., triangle) as a Yield traffic sign and the tolerance sign was the same shape (i.e., octagon) as a Stop traffic sign. Both signs were placed on the non-stimulated hand side of the algometer, with the threshold sign on the inside closest to the algometer and the tolerance sign on the outside.

\section{Measures}

Self-report. Four self-report questionnaires were given to participants to further understand the relation between verbal report measures of fear or pain, anxiety about painful episodes, fear of anxiety sensations and situations, and depression to verbal reports of fear and pain, psychophysiology, and overt behavior. In an extensive review by Vlaeyen and Linton (2000), fear of pain, pain anxiety, and anxiety sensitivity were determined to be useful in understanding pain avoidance behavior. Furthermore, 
because the prevalence rate of depression has been shown to be extremely high with chronic pain patients (Polatin, 1991), this construct was assessed to better understand its potential influence on pain responding within this population.

Fear of Pain Questionnaire-III (FPQ-III). The FPQ-III (McNeil \& Rainwater, 1998) is a 30-item self-report inventory designed to assess individual's fear of a variety of different stimuli that produce pain. A total score (range: 30-150) and three subscale scores (i.e., fear of Severe Pain, Minor Pain, and Medical Pain) are derived, with higher scores indicating greater fear of pain. On a five point Likert-type scale $(1=$ not at all to $5=$ extreme), respondents indicate the degree to which they experience fear regarding pain-relevant stimuli. Good test-retest, internal consistency, and predictive validity have been reported (Hursey \& Jacks, 1992; McNeil \& Rainwater, 1998; Sperry-Clark, McNeil, \& Ciano-Federoff, 1999).

Pain Anxiety Symptom Scale (PASS). The PASS (McCracken, Zayfert, \& Gross, 1992) is a 40 item self-report measure designed to assess individual's anxiety related to pain problems, events, and stimuli. A total score (range: 0-200) and four subscale scores (i.e., Cognitive Anxiety Symptoms related to the pain experience, Escape and Avoidance responses to reduce pain, Fearful Appraisals of pain, and Physiological Anxiety symptoms related to pain) are derived, with higher scores indicating greater painrelated anxiety. On a six-point Likert-type scale $(0=$ never to $5=$ always $)$, respondents indicate the degree to which they experience anxiety regarding pain-relevant stimuli. Previous research has demonstrated the PASS to yield four internally consistent subscales with adequate test-retest reliability (McCracken, Gross, Sorg, \& Edmunds, 1993). The validity of the total and four subscale scores is supported by significant positive correlations with measures of general anxiety, pain, and disability (McCracken et al., 1992).

Anxiety Sensitivity Index (ASI). The ASI (Reiss, Peterson, Gursky, \& McNally, 1986) is a 16-item self-report questionnaire designed to assess the degree to which individual's are concerned about the possible negative consequences of anxiety symptoms. A total score (range: $0-64$ ) is derived, with higher scores indicating concern of anxiety symptoms. On a five-point Likert-type scale $(0=$ very little to $4=$ very much), respondents indicate their sensitivity to anxiety symptoms. The ASI has high levels of 
internal consistency and good test-retest reliability (Peterson \& Reiss, 1992). Research indicates that the factor structure of the ASI is comprised of three lower-order factors (i.e., Physical, Psychological, and Social Concerns), which all load on a single higher-order factor (Global Anxiety Sensitivity; Stein, Jang, \& Livesley, 1999). The total and subscale ASI scores are distinct from trait anxiety and are commonly used as indices of anxiety sensitivity (Schmidt, 1999).

Beck Depression Inventory-II (BDI-II). The BDI-II (Beck, Steer, \& Brown, 1996) is a 21-item selfreport questionnaire in which respondents indicate on a four-point Likert-type scale $(0=$ minimal to $3=$ severe) the degree to which they are experiencing depressive symptoms. A total score is derived (range: 0 -63) by summing each item with high scores indicating greater depressive symptoms. The BDI-II has excellent internal consistency and good test-retest reliability (Beck et al., 1996).

Threshold. Pain threshold time was defined and measured as the moment the participant experienced any pain at all in their finger (i.e., any pain rating above a raring of " 0 ") and physically touched the threshold sign. If the participant forgot to touch the sign, their first verbal report of pain greater than " 0 " was recorded as their threshold time for that condition. If pain reports were " 0 " throughout the condition and the threshold sign was never touched, then threshold was considered to be $300 \mathrm{~s}$, or the duration of the pain task.

Tolerance. Pain tolerance behavior was defined and measured as the maximum amount of time the participant endured the pain stimulation, indicated by touching the tolerance sign or verbally saying "stop." If the participant never touched the tolerance sign and endured the pain stimulation for the duration of the condition, their tolerance time for that condition was considered to be $300 \mathrm{~s}$.

Fear and pain verbal reports. Fear and pain verbal reports were obtained from participants with the assistance of the aforementioned NRS. Participants were instructed to rate the pain only in the finger currently being stimulated and rate their fear of the pain associated with that stimulation. If a participant did not avoid or escape a condition, there was a total of 26 verbal reports (i.e., 13 pain and 13 fear) given per condition. Expected pain and fear ratings were obtained for conditions once all the materials were placed on the table in front of the participant and before the instructions read for that condition. After instructions were read for that condition, pre-stimulation fear and pain ratings were obtained. Once 
pain stimulation began, fear and pain ratings were obtained every 30 seconds until the end of the 5 minute condition, or the participant escaped. Thirty seconds after the condition was terminated, poststimulation fear and pain ratings were obtained. If participants escaped the pain stimulation, they were asked to report their pain and fear rating at the moment they touched the tolerance sign.

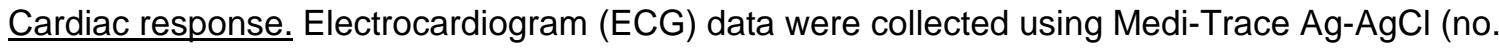
GC-11) pregelled disposable foam electrodes attached to the participant's skin surface to the right and left of the sternum just below the clavicle, and on the left side of the chest at the last palpable rib as a ground. An IBM compatible microcomputer, fitted with a Scientific Solutions Labmaster interface board and specialized software (Cook, Atkinson, \& Lang, 1987), timed procedures and controlled a Coulbourn Instruments (Cl) no. S75-01 High Gain Bioamplifier/Coupler that filtered and amplified the ECG. The signal was then input to a Schmitt trigger apparatus (including a Cl no. S21-06 Bipolar Comparator and no. S51-12 Dual Retriggerable One-Shot) that output a pulse after detecting an R wave in the ECG. Interbeat intervals were therefore recorded using this interface apparatus, and later transformed into beats per minute (bpm).

$\underline{\text { Instructions }}$

The instructions were derived using the McGill Pain Questionnaire (MPQ: Melzack, 1975) to provide word descriptors of pain. The selection of specific word choice was based on research by Melzack and Torgerson (1971), Kremer and Atkinson (1984), and Gaffney et al. (1987) that suggests many words, taken from the MPQ, to describe different pain intensity levels. Words that were highest in agreement, as relating to areas of sensory, affective, and evaluative pain, were selected to be used in the instructions for high and low fear. Also, these instructions were designed to produce low demand on the participant in all conditions, allowing them to stop at any moment during stimulation. See Appendix $A$ for high, low, and neutral verbal fear intensity instructions.

\section{Procedure}

Participant recruitment. The primary experimenter reviewed patient's medical charts to determine if they met exclusion criteria for the present study. If their medical charts did not indicate that they meet these criteria, they were telephoned at home to set up an appointment to participate in the 
study immediately prior to or immediately following their next scheduled appointment with the clinic. Appendix B shows the standardized procedure for the recruitment of participants.

Experiment. Figure 3 displays the procedural steps used in the current study. When patients arrived to participate in the study, they were seated in the experimental room and asked if they met any of the exclusion criteria. If they did, they were informed that for their safety they could not participate and were thanked for their time and interest in the study. However, if they did not meet exclusion criteria, the principle experimenter reviewed the consent form (see Appendix C) and gave a brief demonstration of the algometer. During the demonstration, the two weights to be used in the four conditions were shown to the participant; however, only the $1000 \mathrm{~g}$ large red container and the $500 \mathrm{~g}$ small blue container were revealed. The other containers (i.e., $500 \mathrm{~g}$ large red container, the $1000 \mathrm{~g}$ small blue container, and the $750 \mathrm{~g}$ tan container) remained hidden in a briefcase next to the principle experimenter. Hiding the other containers was necessary to help ensure that the fear manipulation would be effective in the low fear / high pain and high fear / low pain conditions.

Once informed consent was obtained, a brief semi-structured interview was conducted to obtain demographic and additional identifying information. Appendix $D$ shows the demographic form used to collect and record these data. Following the demographic interview, the four above stated questionnaires were given. Next, the initial exposure was conducted. The participant sat at a small table with the principle experimenter seated directly across the table facing them. The computer assistant who operated the physiological equipment sat behind the principle experimenter at another table and faced away from the participant. The materials on the table in front of the participant included the algometer, pain and fear rating scales, threshold and tolerance signs, and the tan $(750 \mathrm{~g})$ weight, all in their designated positioned. During the initial exposure, the participant's index finger on the hand not to be used in the first condition was used; it was determined prior to participation which hand and finger would be used and what order the four conditions would occur in using a Latin Square procedure similar to that used by Myrtek and Spital (1986) and described by Keppel (1991).

Once the participant's finger was in the algometer, without the weight resting on top, they were asked what they expected their highest pain and fear ratings to be during the stimulation in this 
condition. Then, the neutral instructions for the initial exposure were read to the participant (see Appendix B for neutral instructions). Following the instructions, current pain and fear ratings were obtained. After participants reported their pain and fear ratings, the weight was place on top of the algometer and the timer was started. Participants were asked to verbally report their pain and fear ratings every 30 seconds, once they touched the threshold or tolerance signs, and 30 seconds after the stimulation was discontinued. If participants did not discontinue the stimulation (i.e., escape) before the end of the 5-min condition, there would be a total of 13 pain and fear ratings obtained.

Following the initial exposure condition, all materials were removed from the table and placed out of view in a briefcase next to the principle experimenter. Participant questions were answered and then ECG sensors were attached as specified. Once the sensors were securely attached and the instrumentation to the physiological equipment adjusted to the individual, participants were asked to relax to obtain a 5-min prebaseline rest period, followed by a 2-min precondition 1 baseline. At the end of the precondition 1 baseline, the algometer, pain and fear rating scales, threshold and tolerance signs, and weight used for the first condition were placed in their designated position on the table. Participants then were asked to report their expectation ratings and the principle experimenter read the instructions for that condition. Lastly, pain and fear ratings were obtained just prior to placing the weight on the algometer for that condition.

From this point in the procedure, all the steps were the same as those performed in the initial exposure, specific to the condition the participant was in. Following the final condition, a 5-min postbaseline rest period was initiated. Then the participant was debriefed, questions were answered, and they were thanked for their time and interest in the study. See Figure 3 for illustration of procedure.

\section{Results}

\section{Experimental Design}

A $2 \times 2$ within subject design was used with two levels of fear (low and high) and two levels of pain (low and high). A Latin Square procedure, similar to Myrtek and Spital (1986) and described in Keppel (1991), was used to determine condition, hand, and finger order for participants. 


\section{Data Processing and Analysis Plan}

Complete data were collected for all 40 participants on self-report questionnaires, verbal reports of fear and pain, and heart rate; each participant initiated all four conditions. Therefore, the analyses of self-report questionnaires, verbal reports, heart rate, and overt behaviors include 40 participants. Table 4 summarizes participant demographics.

Avoidance was defined as a participant stopping a condition before the pressure pain stimulation was initiated. Escape was defined as a participant stopping pressure stimulation after it started but before the end of the five minute condition. No participant avoided any condition; however, 11 males (27.5\%) and 15 females (37.5\%) escaped high fear / high pain, 4 males (10\%) and 9 females (22.5\%) escaped high fear / low pain, 11 males (27.5\%) and 14 females (35\%) escaped low fear / high pain, and 4 males (10\%) and 9 females (22.5\%) escaped low fear / low pain conditions. By escaping these conditions, participants displayed, through overt behavior, the aversiveness of the particular experience(s).

Table 5 summarizes data obtained from the three modalities of responding by condition. In all analyses, significant repeated measures analyses of variance (ANOVA) were followed-up by NewmanKeuls tests at the .05 alpha level, as appropriate.

\section{Data Reduction}

Change scores were computed for verbal reports of fear and pain and for heart rate in each of the four conditions. To obtain change scores for verbal reports of fear, the first pre-fear rating given by the participant (i.e., pre-fear rating from the initial exposure condition) was subtracted from the mean verbal report of fear across the 30-s intervals of each condition. Verbal reports of fear were based on a 0 ("No fear") to 100 ("Worst fear imaginable in this situation") rating scale. The same procedure was performed to obtain verbal report change scores of pain by subtracting the pre-pain rating from the initial exposure condition from the mean verbal report of pain across the 30-s intervals of each condition. As with verbal reports of fear, pain reports were based on a 0 to 100 rating scale with 0 meaning "No pain" and 100 meaning "Worst imaginable pain in this situation." Lastly, to calculate heart rate change scores, the median heart rate value from the initial baseline was subtracted from the median heart rate value 
recorded in each of the four conditions.

$\underline{\text { Initial Self-Report Instruments }}$

Table 6 presents data from the four self-report instruments (i.e., FPQ-III, PASS, ASI, and BDI-II) for all 40 participants. Overall, the mean total scores for all measures are similar to those reported in other investigations studying individuals with chronic pain disorders (e.g., Asmundson, Jacobson, Allerdings, \& Norton, 1996; McCracken et al., 1993; and McNeil, \& Rainwater, 1998). More specifically, all scores from the present study are within one standard deviation of the scores observed by Zvolensky, Goodie, McNeil, Sperry, and Sorrell (2000) using the same four measures with a heterogeneous chronic pain outpatient population, as shown in Table 6.

\section{Pain Task Data}

Initially, 2 (fear level) X 2 (pain level) X 2 (gender) repeated measures ANOVAs were conducted on each mode of responding (i.e., threshold, tolerance, fear and pain verbal reports, and cardiac response).

Threshold. There was a significant main effect of pain stimulus intensity level on threshold time, $\underline{F}(1,38)=20.20 \underline{p}<.01$, such that higher levels of pain stimulus intensity produced lower threshold times. No other main effects or interactions were significant. Figure 4 shows mean threshold times for participants across each condition. See Appendix E for corresponding ANOVA table.

Tolerance. As with threshold time, there was a significant main effect of pain level on tolerance time, $\underline{F}(1,38)=43.96, \underline{p}<.01$, such that higher levels of pain stimulus intensity produced lower tolerance times. Additionally, there was a significant main effect of gender on tolerance time, $\underline{F}(1,38)$ 4.72, $\underline{\mathrm{p}}<.05$, such that males $(\underline{\mathrm{M}}=228.58, \underline{\mathrm{S}} \underline{\mathrm{n}}=18.97)$ had higher tolerance times than did females $(\underline{M}=170.29, \underline{S D}=18.97)$. No other main effects or interactions were significant. Figure 5 shows mean tolerance times for participants across each condition. Figure 6 shows mean tolerance times for male and female participants across each condition. See Appendix F for corresponding ANOVA table.

Fear and pain verbal reports. Main effects were shown for pain level on both fear verbal reports, $\underline{F}(1,38)=23.30, \underline{p}<.01$, and pain verbal reports, $\underline{F}(1,38)=33.06, \underline{p}<.01$. These main effects indicate that higher levels of pain stimulus intensity produced higher pain and fear verbal reports. No other main 
effects or interactions were significant. Figures 7 and 8 show mean change scores for fear and pain verbal reports, respectively, across each condition. See Appendices $\mathrm{G}$ and $\mathrm{H}$ for corresponding ANOVA tables.

Cardiac response. A significant interaction between fear and pain was observed for heart rate, $\underline{F}(1,38)=7.29, \underline{p}<.01$. A Newman-Keuls test revealed that the high fear / high pain condition elicited higher heart rate change relative to the other three conditions, which did not differ from one another. Also, a significant main effect was shown of pain stimulus intensity level on heart rate, $\underline{F}(1,38)=5.16$, $\underline{\mathrm{p}}<.05$, such that higher pain stimulus intensity levels produced higher heart rate responding. Figure 9 displays mean change scores for heart rate across the four conditions. See appendix I for corresponding ANOVA table.

\section{$\underline{\text { Additional Analyses }}$}

Order effects were controlled in this study's within subject design with the Latin Square procedure already noted. So as to assess for possible order effects, however, some of the data also were analyzed from the perspective of a between subject design. Specifically, only those data from each participant's first condition were analyzed so as to avoid contagion from any preceding conditions. Therefore, there were approximately 10 participants $( \pm 2)$ in each of the following first condition cells: (a) high fear/high pain, (b) high fear/low pain, (c) low fear/high pain, and (d) low fear/low pain. Results from these ANOVAs revealed the same pattern of effects as with the within subject analyses. The only exception was that there was no significant interaction between pain and fear stimulus intensity levels on the heart rate variable. See Appendices J-N for corresponding ANOVA tables.

\section{Discussion}

The main goals of this study were to (a) examine the effects of fear and pain stimulus intensity levels on experimental pain responding and (b) clarify how pain-relevant fear affects pain responding in chronic pain patients. To achieve these goals, fear and pressure pain stimulus intensity levels were manipulated with 40 chronic pain patients. Using a within subject design, four experimental conditions were experienced by every participant. There were three main findings. First, a significant main effect of pain stimulus intensity was found for threshold and tolerance time, verbal reports of fear and pain, and 
heart rate. Second, there was a significant interaction between fear and pain stimulus intensity levels for heart rate. Third, a significant main effect of gender was found for tolerance time. In general, the relative absence of fear effects on pain responding is consistent with findings from previous research (e.g., Arntz et al., 1991; Arntz \& De Jong, 1993; Arntz et al., 1994). Furthermore, the influence of fear on pain observed with heart rate is consistent with other research (e.g., Al Absi \& Rokke, 1991; Williams, 1996). Also, a unique contribution to the research literature on pain has been made by examining how pain and fear stimulus intensity levels affect pain responding in humans. These results are discussed in further detail below with regard to each hypothesis.

\section{Major Findings}

Pain responding sensitive to pain and fear stimulus intensity. The first hypothesis was partially confirmed. Pain responding was sensitive to pain stimulus intensity, however, it was not sensitive to fear stimulus intensity (cf. Rachman \& Lopatka, 1986). When participants experienced high pain stimulus conditions, irrespective of fear level, threshold and tolerance times decreased, verbal reports of fear and pain increased, and heart rate increased. Additionally, when participants experienced low pain stimulus conditions, irrespective of fear level, threshold and tolerance times increased, verbal reports of fear and pain decreased, and heart rate decreased relative to the high pain condition. The findings from the present investigation corroborate results from studies performed by Arntz and colleagues $(1991,1994)$ and Arntz and de Jong (1993) that report no influence of fear on laboratory pain responding (cf. Rhudy, \& Meagher, 2000).

Contrary to Rhudy and Meagher (2000), there were no analgesic effects of fear on pain responding. This finding is somewhat surprising given that pain partly is defined as an emotional response. It only may be that pain responding is not affected by fear stimulus intensity levels, however, when both pain and fear stimulus intensity are considered. If pain stimulus intensity levels were held constant and only fear levels manipulated (i.e., presence or absence) as in previous studies (e.g., Al Absi \& Rokke, 1991; Arntz \& de Jong, 1993), there may have been a significant influence of fear on pain (e.g., Crombez et al., 1999). When both pain and fear levels are manipulated, however, pain stimulus intensity may have precedence over emotional influence of pain (cf., Bolles, \& Fanslow, 1980). 
Unpredicted effect of stimulus intensity on gender. Although it was not hypothesized that there would be significant effects of gender on pain responding, there was a significant main effect of gender on tolerance time. That is, male participants consistently had greater tolerance times then females across the each condition. Gender effects in the experimentation of pain are not uncommon and have been shown to complexly influence verbal reports and physiological responses (Rollman, Lautenbacher, \& Jones, 2000). These effects were not controlled in the present study, which may partly explain why there are inconsistent gender effects across modes of responding (e.g., verbal reports and heart rate). With more specific consideration of gender effects on pain responding, pain and fear stimulus intensity levels may be better understood between genders.

Additive effects of high fear and high pain. The second hypothesis predicted that additive effects of high pain and high fear together would lead to the greatest pain responding of all. As with the first hypothesis, the second was partially confirmed. There were not additive effects of high fear and high pain across all three modes of responding. Additive effects did not occur, for example, with threshold or tolerance times, or verbal reports of fear and pain. When examining heart rate results, however, an additive effect of high fear and pain is evidenced. Participant heart rate increased significantly in the high fear/high pain condition relative to the other three conditions, which did not significantly differ from one another. This effect gives some support to research by Rachman \& Lopatka (1986) who found fears to summate. This is true only when pain and fear stimulus intensity levels are high.

If emotions such as fear do summate with pain to increase heart rate responding, then why did this effect not show in other modes of responding (i.e., overt behavior and verbal reports)? To better understand this inconsistency across response modalities, Mohlman and Zinbarg (2000) discussed the importance of examining physiological responding when assessing fear responding in humans. They suggest that because patients are often imperfect in their ability to accurately and reliably self-report fear, physiological responding may be a better indicator than overt behavior or verbal reports of fear. Therefore, although there was no additive effect of high pain and fear on pain responding across all three modes of responding, it may be likely that additive effects are still possible. Thus, looking to heart 
Stimulus Intensity, Pain, and Fear 20

rate and other physiological responses to pain may improve our understanding of the additive effects of high pain and fear.

\section{Limitations and Future Directions}

The first limitation of this study is the difficulty in producing a valid and reliable fear response in humans (Vlaeyen \& Linton, 2000). Given that fear is defined as multidimensional, and as a combination of physiological, behavioral, and cognitive responses (McNeil et al., 1994), it would be expected to see significant fear effects across each response mode. It was noted, however, that several participants acknowledged that they did not experience fear because they could stop the pain stimulation at anytime. Previous research has shown control over aversive stimuli and situations can significantly affect responding in that situation (Zvolensky, Eifert, \& Lejuez, in press; Zvolensky, Eifert, Lejuez, \& McNeil, 1999). Specifically, Zvolensky et al. (1999) found that individuals demonstrated decreased anxious responding (i.e., verbal reports of anxiety and escape) when offset control of carbon dioxide-enriched air was present. They also found that this decrease in anxious responding was not demonstrated in heart rate, which is consistent with the results of the present investigation. Therefore, decreasing perception of offset control over the pain stimulus might increase the effects of fear stimulus intensity levels across modes of responding.

A second limitation is the small number of participants and that this may limit robustness of interaction effects of pain and fear stimulus intensity levels on pain responding in this sample. Although the within subjects design will help account for this potential problem, more participants using the same experimental design or a between subjects design may be beneficial in obtaining larger effects, and particularly of the fear variable.

The present investigation also suffers from ecological validity issues. This limitation partly is related to the first stated limitation of this investigation. Pressure pain and fear stimulation levels were induced in the contrived environment of a pain treatment center. There are several stimuli in this immediate environment that likely were associated in some way with pain reduction. For example, being in the "safe" setting of a hospital with medical doctors nearby may have inadvertently influenced pain responding in some participants. Furthermore, the fear of pain induced in this study was not specific to 
the participant's chronic pain problem. As previous research has shown, pain-relevant fear is more likely to increase pain responding (e.g., Al Absi \& Rokke, 1991) while pain-irrelevant fear is morel likely to function as a distractor and decreasing pain responding (e.g., Eccleston, 1994). Although the fear stimulus in this study was "relevant" to the pain stimulus, it was not relevant to the participant's chronic pain condition.

Future research would benefit from increasing the ecological validity of this type of experimentation by measuring, for example, the effects of pain and fear stimulus levels on pain responding in applied settings such as a dental office. In this model, participants would be persons with extreme dental fear and no dental fear (i.e., analogous to high and low fear conditions in the present study) and pain conditions would be an extremely painful dental procedure (e.g., root canal) and a relatively painless procedure (e.g., dental cleaning). By adopting this type of research model in which a naturally pain-relevant and fearful environment is used, greater control over ecological validity likely would be met.

Finally, it should be pointed out that the present study examined the effects of experimentally induced acute pain with chronic pain patients. As previously mentioned, acute and chronic pain are quite different in other respects than just duration. Whereas acute pain functions as a signal or an establishing operation for an individual to behave in a certain manner to prevent further tissue damage or to allow for healing of an injury, chronic pain is the persistence of the pain signal despite physical recovery.

Furthermore, chronic pain may be relatively more influenced by psychological and social variables than acute pain. It is not to say that acute pain is not influence by these variables, but rather that acute and chronic pain may be affected differently by psychological and social influences. Acute pain also may be relatively more influenced by physiological properties of pain such as neurological pathways compared to chronic pain. Therefore, to truly understand the effects of fear and stimulus intensity on chronic pain, an experimental procedure must be developed to delve into this issue. To date, most studies have examined the effects of different variables on acute pain. 


\section{$\underline{\text { Conclusions }}$}

Pain and fear stimulus intensity levels were manipulated and pain and fear responding were recorded in chronic pain patients. Pain stimulus intensity, irrespective of fear stimulus intensity, was the most influential variable in producing pain responding in these participants. High fear stimulus intensity, however, interacted with high pain stimulus intensity to increase heart rate relative to other conditions. This effect was not demonstrated in other modes of responding (e.g., overt behavior), but is consistent with previous research when offset control over aversive stimuli is considered (Zvolensky et al., 1999).

Considerably more research further is required in the area of fear induction. Specifically, research needs to investigate how to reliably manipulate fear in an experimental setting. Particularly if we truly are to understand how fear influences pain responding, an effective methodology of evoking pain-relevant fear must be established. Reliably inducing appropriate levels of fear has been a limitation in previous research (e.g., Arntz et al. 1991) and was as well in the present study. Otherwise, more ecologically valid methods of research, such as those already proposed, are needed to circumvent this difficult research dilemma.

Despite the limitation of this study, the findings are important and provide further insight into how pain and fear interact in producing the entire pain experience. With certain improvements in methodology and future research efforts, researchers and clinicians will someday have a clearer understanding of how levels of pain and negative emotions influence pain such that the quality of life for chronic pain patients can be improved. 


\section{References}

Al Absi, M. A., \& Rokke, P. D. (1991). Can anxiety help us tolerate pain? Pain, 46, 43-51.

American Psychiatric Association. (1994). Diagnostic and statistical manual of mental disorders

(4th ed.). Washington, DC: Author.

Arntz, A., \& De Jong, P. (1993). Anxiety, attention, and pain. Journal of Psychosomatic

Research, 37, 423-432.

Arntz, A., Dreessen, L., \& De Jong, P. (1994). The influence of anxiety on pain: Attentional and attributional mediators. Pain, 56, 307-314.

Arntz, A., Dreessen, L., \& Merckelbach, H. (1991). Attention, not anxiety, influences pain. Behaviour Research and Therapy, 29, 41-50.

Asmundson, J. G., Jacobson, S. J., Allerdings, M. D., \& Norton, G. R. (1996). Social phobia in disabled workers with chronic musculoskeletal pain. Behaviour Research and Therapy, 34, 939-943.

Barlow, D. H. (1988). Anxiety and its disorders: The nature and treatment of anxiety and panic. New York: Guilford Press.

Barlow, D. H. (1991). Disorders of emotion. Psychological Inquiry, 2, 58-71.

Beck, A. T., Steer, R. A., \& Brown, G. K. (1996). Manual for the Beck Depression Inventory-II. San Antonio, TX: The Psychological Corporation.

Bolles, R. C., \& Fanselow, M. S. (1980). A perceptual-defensive-recuperative model of fear and pain. Behavioral and Brain Sciences, 3, 291-323.

Carter, L. E., McNeil, D. W., Vowles, K. E., Sorrell, J. T., Turk, C., \& Ries, B. J. (2000). Effects of emotion on pain reports, tolerance, and physiology. Manuscript in preparation.

Cook, E. W., III, Atkinson, L., \& Lang, K. G. (1987). Stimulus control and data acquisition for IBM PC's and compatibles. Psychophysiology, 24, 726-727. (Abstract)

Crombez, G., Eccleston, C., Baeyens, F., \& Eelen, P., (1998). Attentional disruption is enhanced by the threat of pain. Behaviour Research and Therapy, 36, 195-204.

Crombez, G., Vlaeyen, J. S., Heuts, P. T.\& Lysens, R. (1999). Pain-related fear is more disabling than pain itself: Evidence on the role of pain-related fear in chronic back pain disability. Pain, 80, 329- 
339.

Eccleston, C. (1994). Chronic pain and attention: A cognitive approach. British Journal of Clinical Psychology, 33, 535-547.

Eifert, G. H., Lejeuz, C. W., \& Bouman, T. K. (1998). Somatoform disorders. In A. Bellack, M. Hersen, \& P. Salkovskis (Eds.), Comprehensive clinical psychology (pp. 543-565). New York, NY: Elsevier Science.

Gaffney, T. J., Foenander, G., Reade, P. C., \& Burrows, G. D. (1987). A study of the words used to describe pain. Australian Dental Journal, 32, 326-330.

Gross, R. T., \& Collins, F. L. (1981). On the relationship between anxiety and pain: A methodological confounding. Clinical Psychology Review, 1, 375-386.

Hadjistavropoulos, H. D., \& Craig, K. D. (1994). Acute and chronic low back pain: Cognitive, affective, and behavioural dimensions. Journal of Consulting and Clinical Psychology, 62, 341-349.

Hursey, K. G., \& Jacks, S. D. (1992). Fear of pain in recurrent headache suffers. Headache, 32, 283-286.

Keppel, G. (1991). Design and analysis: A researcher's handbook. (3rd ed.). NJ: Prentice-Hall. Kremer, E. F., \& Atkinson, J. H. (1984). Pain language: Affect. Journal of Psychosomatic Research, 28, 125-132.

McCracken, L. M., Gross, R. T., Sorg, P. J., \& Edmunds, T. A. (1993). Prediction of pain in patients with chronic low back pain: Effects of inaccurate prediction and pain-related anxiety. Behaviour Research and Therapy, 31, 647-652.

McCracken, L. M., Zayfert, C., \& Gross, R. T. (1992). The Pain Anxiety Symptoms Scale: Development and validation of a scale to measure fear of pain. Pain, 50, 67-73.

McNeil, D. W., Turk, C. L., \& Ries, B. J. (1994). Anxiety and fear. Encyclopedia of Human Behavior, 1, 151-163.

Melzack, R. (1975). The McGill Pain Questionnaire: Major properties and scoring methods. Pain, 1, 277-299.

Melzack, R., \& Torgerson, W. S. (1971). On the language of pain. Anesthesiology, 34, 50-59. 
Melzack, R., \& Wall, P. D., (1965). Pain mechanisms: A new theory. Science, 150, 971-979.

Melzack, R., \& Wall, P. D., (1982). The challenge of pain. New York: Basic Books.

Mohlman, J., \& Zinbarg, R. E. (2000). What kind of attention is necessary for fear reduction: An empirical test of the emotional processing model. Behavior Therapy, 31, 113-133.

Myrtek, M., \& Spital, S. (1986). Psychophysiological response patterns to single, double, and triple stressors. Psychophysiology, 23, 663-671.

Peterson, R. A., \& Reiss, S. (1992). Anxiety Sensitivity Index Manual (2nd ed.). Worthington, $\mathrm{OH}$ : International Diagnostic Systems.

Polatin, P. B. (1991). Affective disorders in back pain. In T. G. Mayer, V. Mooney, \& R. J. Gatchel (Eds.), Contemporary conservative care for painful spinal disorders (pp. 149-154). Malvern, PA: Lea \& Febiger.

Poree, L. R., Angst, M. S., \& Dyck, J. B. (1996). Evaluation of a new experimental electrical pain model in humans. $\underline{8}^{\text {th }}$ World Congress on Pain, Vancouver. Abstracts page $332(5)$, International Association for the Study of Pain Press, Seattle.

Rachman, S., \& Lopatka, C. (1986). Do fears summate? - III. Behaviour Research and Therapy, 24, 653-660.

Reiss, S., Peterson, R. A., Gursky, M., \& McNally, R. J. (1986). Anxiety, sensitivity, anxiety frequency, and the prediction of fearfulness. Behaviour Research and Therapy, 24, 1-8.

Rhudy, J. L., \& Meagher, M. W. (2000). Fear and anxiety: Divergent effects on human pain thresholds. Pain, 84, 65-75.

Rollman, G. B., Lautenbacher, S., \& Jones, K. S. (2000). Sex and gender differences in responses to experimentally induced pain in humans. In R. B. Fillingim (Ed.), Sex, gender, and pain: Vol. 17. Progress in pain research and management (pp. 165-190). IASP Press, Seattle, WA.

Schmidt, N. B. (1999). Examination of differential anxiety sensitivities in panic disorder: A test of anxiety sensitivity subdomains in predicting fearful responding to a $35 \% \mathrm{CO}_{2}$ challenge. $\underline{\text { Cognitive }}$ Therapy and Research, 23, 3-19.

Sperry-Clark, J. A., McNeil, D. W., \& Ciano-Federoff, L. (1999). Assessing chronic pain patients: 
The Fear of Pain Questionnaire - III (pp. 293-305). In L. Vandercreek and T. L. Jackson (Eds.), Innovations in Clinical Practice: A Source Book. Sarasota, FL. Professional Resources Press.

Stein, M. B., Jang, K. L., \& Livesley, W. J. (1999). Heritability of anxiety sensitivity: A twin study. American Journal of Psychiatry, 156, 246-251.

Tollison, D. C., Hinnant, \& Kriegel, M. L. (1991). Psychological concepts of pain. In T. G. Mayer, V. Mooney, \& R. J. Gatchel (Eds.), Contemporary conservative care for painful spinal disorders (pp. 133142). Malvern, PA: Lea \& Febiger..

Tollison, D. C., Kriegel, M. L., \& Downie, G. R. (1985). Chronic low back pain: Results of treatment at the pain therapy center. Southern Medical Journal, 78, 1291-1300.

Turk, D. C. (1996). Biopsychosocial perspective on chronic pain. In D. Gatchel \& D. Turk (Eds.), Psychological approaches to pain management: A practitioner's handbook (pp. 3-32). NY: Guilford Press.

Turk, D. C., \& Melzack, R. (1992). The measurement of pain and the assessment of people experiencing pain. In D. Turk \& R. Melzack (Eds.), Handbook of pain assessment (pp. 3-12). New York: Guilford Press.

Vlaeyen, J. W., \& Linton, S. J. (2000). Fear-avoidance and its consequences in chronic musculoskeletal pain: A state of the art. Pain, 85, 317-332.

Weisenberg, M. (1997). Psychological intervention for the control of pain. In S. Rachman (Ed.), Best of Behaviour Research and Therapy: A collection of landmark articles (pp. 107-118). NY: Elsevier Science Ltd.

Williams, D. (1996). Acute pain management. In D. Gatchel \& D. Turk (Eds.), Psychological approaches to pain management: A practitioner's handbook (pp. 55-77). NY: Guilford Press.

Zvolensky, M. J., Eifert, G. H., \& Lejuez, C. W. (in press). Prediction and control: Operational definitions for the experimental analysis of anxiety. Behaviour Research and Therapy.

Zvolensky, M. J., Eifert, G. H., Lejuez, C. W., \& McNeil, D. W. (1999). The effects of offset control over $20 \%$ carbon dioxide-enriched air on anxious responding. Journal of Abnormal Psychology, 108, 624-632. 
Stimulus Intensity, Pain, and Fear 27

Zvolensky, M. J., Goodie, J. L., McNeil, D. W., Sperry, J. S., \& Sorrell, J. T. (in press). Anxiety sensitivity in the prediction of pain-related fear and anxiety in a heterogeneous chronic pain population. Behaviour Research and Therapy.

Zvolensky, M. J., Gross, R. T., Sorrell, J. T., Boggess, J., \& Sperry, J. A. (2000). Multidisciplinary occupational rehabilitation for treatment refractory chronic pain patients: Initial outcome findings and short-term follow-up assessment. Manuscript in preparation. 


\section{Appendix A}

Verbal Fear Intensity Instructions

\section{$\underline{\text { High fear intensity instructions }}$}

Do your best to endure any pain you may experience for the duration of this condition. If at any point you become too uncomfortable to continue, please remember that you are permitted to stop at any time by placing your hand on the red "Stop" sign in front of you.

Over the next few minutes you will have your finger in this pressure device. You will likely experience this pain as agonizing and horrible. Although you may experience this pain, the stimulation will not produce any lasting physical damage to your skin or any part of your body. You may consider this pounding sensation to be an excruciating and unbearable experience, producing a high level of anxiety.

\section{Low fear intensity instructions}

Do your best to endure any pain you may experience for the duration of this condition. If at any point you become too uncomfortable to continue, please remember that you are permitted to stop at any time by placing your hand on the red "Stop" sign in front of you.

Over the next few minutes you will have your finger in this pressure device. You will likely experience this pain as mild and annoying. Although you may experience this pain, the stimulation will not produce any lasting physical damage to your skin or any part of your body. You may consider this pressing sensation as a tiring and discomforting experience, producing a low level of anxiety.

\section{Neutral fear intensity instructions}

Do your best to endure any pain you may experience for the duration of this condition. If at any point you become too uncomfortable to continue, please remember that you are permitted to stop at any time by placing your hand on the red "Stop" sign in front of you.

Over the next few minutes you will have your finger in this pressure device. Although you may experience some pain, the stimulation will not produce any lasting physical damage to your skin or any part of your body. 
Stimulus Intensity, Pain, and Fear 29

Appendix B

Patient Telephone Contact/Recruitment Protocol

"May I speak with [name of participant] please? (Once potential participant is on the phone) My name is [name of investigator calling] and I'm calling from the Pain Treatment Center here in Morgantown. How are you this morning/afternoon? (Wait for patient response) Well, I was calling to remind you of your appointment here on [date and time of their appointment] and to tell you about a research study that we are conducting at the clinic that is focusing on how anxiety and fear affect pain in people with chronic pain problems. Do you have about two minutes to hear about the study and to see if you might be interested in participating?"

If patient says "no," thank them for their time and remind them again of the date and time of their appointment.

If patient says "yes," say: "Well, we are working to try and better understand how anxiety and fear affect people who have chronic pain problems. To do this, we are asking people to fill out four questionnaires and then to engage in four different pressure stimulation tasks. Each pressure stimulation task involves putting weight on your finger while you rate your fear and pain levels. This study will take about $1 \frac{1}{2}$ hours of your time to complete. You likely will benefit by learning how anxiety and fear affect your pain. Furthermore, to help compensate you for your time in participating, we will be paying you $\$ 25.00$. Would this be something that you would be interested to participate in?"

If patient says "no," thank them for their time and remind them again of the date and time of their appointment.

If patient says "yes," say: "Would you be able to come in 2 hours before or stay 2 hours after their appointment?"

If patient says "yes," schedule them accordingly. If patient says "no," ask them when a good time would be for them. 
Stimulus Intensity, Pain, and Fear 30

Appendix C

$\underline{\text { Consent Form }}$

Effects of Stimulus Intensity and Fear Level on Pain Responding in Chronic Pain Patients

Introduction. I, , have been invited to participate in this

research study which has been explained to me by . I understand that my participation will require me to complete several forms, prior to my participation in the experimental procedure. This research is being conducted to fulfill requirements for John T. Sorrell's master's thesis in clinical psychology at West Virginia University.

Purposes of the Study. I understand that the purpose of this study is to identify how different levels of pain and fear influence emotions and thoughts.

Description of Procedures. I will be one of 40 chronic pain patients at the West Virginia University School of Medicine Pain Management Center who will participate in this study. I understand that the study involves only one session that will last approximately 60 minutes, which includes a brief review of my hospital chart to record information (e.g., medications with anti-anxiety properties) that may affect my participation in this study. My participation in this research will involve filling out three brief questionnaires, and recording my level of fear and pain several times during the session. I may see all of the questionnaires before signing this consent form and I do not have to answer any questionnaires or questions that I find objectionable.

I understand that sensors will be taped to my chest and side to record heart rate throughout the study. At four separate times during the procedure, I understand that I will place one of my fingers in an "algometer" pressure device, which will first be demonstrated to me before I consent. The algometer is an apparatus made of wood and plastic that is used to produce a mounting pressure on the finger placed in the device. The hand rests on a wooden platform while the stimulated finger rests on the same platform between two smaller pieces of wood. Resting on top of the stimulated finger is a blunt plastic wedge with a small wooden platform attached to the top of the plastic. When this portion of the device is in place, various weights can be set on top of the platform to produce different degrees of pressure at the site of the finger where the plastic wedge is located. This device produces a building discomfort and temporary pain, but causes no lasting damage or lasting pain. During the entire session, the total amount of time possible that I may be exposed to this pressure stimulation is 20 minutes (i.e., 5 minutes on each of four different fingers). I understand that at any point during this stimulation, I may stop the procedure.

Risks and Discomforts. There are no known or expected risks from participation in this study. Temporary discomfort is expected when I am exposed to pressure stimulation. The sensations I may experience when exposed to this stimulation is similar to a progressively painful, pinching, and building pressure. These sensations are expected to disappear quickly when the stimulation is discontinued.

Financial Considerations. There are no special fees for participating and I understand that I will receive $\$ 25.00$ following my participation in the present study. 
Appendix C continued

Effects of Stimulus Intensity and Fear Level on Pain Responding in Chronic Pain Patients

Alternatives. I understand that I am not required to partake in this study. An alternative that I have is to not participate.

Benefits. The benefits that I will gain by participating in this study include the knowledge of experimentation procedures and the functioning of a psychological laboratory and knowledge that my participation may benefit others.

Contact Persons. For more information about this research, I may contact John T. Sorrell, B.A. at 2932001 (ext. 870), or his supervisor, Daniel W. McNeil, Ph.D. at 293-2001 (ext. 622). For information regarding my rights as a research participant, I may contact the Executive Secretary of the Institutional Review Board at 293-7073.

Confidentiality. I understand that any information about me obtained, as a result of my participation in this research, will be kept as confidential as legally possible. I also understand that my research records, just like hospital records, may be subpoenaed by a court order or may be inspected by federal regulatory authorities. In any publication that results from this research, neither my name nor any information from which I might be identified will be published without my consent.

Voluntary Compensation Clause. If injury occurs as a result of this research, treatment will be available. No compensation will be voluntarily provided by the investigator, West Virginia University, or other associated organizations and corporations.

Voluntary Participation. Participation in this study is voluntary. I understand that I am free to withdraw my consent to participate in this study at any time. Refusal to participate or withdrawal will involve no penalty or loss of benefits and will not affect my treatment at the clinic. I have been given the opportunity to ask questions about the research, and I have received answers concerning areas I did not understand. Upon signing this form, I will receive a copy.

I willingly consent to participate in this study.

Signature of Participant

Signature of Investigator or Investigator's Representative
Date

Date 
Appendix D

Demographics Form

Demographics Sheet for Study PA-01

Date

Participant number
Reviewer

Chart \#

Gender:

1. Male 2. Female

DOB/Age:

Height:

Weight:

Ethnicity:
1. Caucasian
2. African-American
3. Hispanic
4. Asian
5. Native American
6. Other

Marital Status:
1. Single
2. Married
3. Divorced
4. Separated
5. Widowed
6. Live-in-partner

Number of Children:

Family History (i.e., Any family members with chronic pain):
1. Mother
2. Father
3. Sister
4. Brother
5. Daughter
6. Son 
Appendix D continued

Handedness:

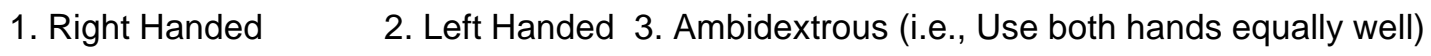

Hand Preference if Ambidextrous:
1. Right
2. Left
3. Not applicable

Educational Level:

1. Some high school

4. Training or technical school

7. Graduate training
2. High school diploma

5. Some college
3. GED

6. Bachelor's degree

Occupation at time pain began and now:

Origins of pain:

Length of Time That You Have Been In Pain:

Location or locations of chronic pain:

Overall pain rating, on scale from 0 to 100 , since pain started:

(0 = No Pain, $100=$ Maximum Pain $)$

Overall pain rating, on scale from 0 to 100 , today:

(0 = No Pain, 100 = Maximum Pain)

Ever any legal proceedings regarding pain:
1. Yes
2. No
If so, when:

Legal proceedings now:
1. Yes
2. No

Ever received payment because of pain:
1. Yes
2. No
If so, when: 


\section{Appendix D continued}

Receiving payments now because of pain:

1. Yes 2. No

All Medical Diagnoses:

Current Medications:

Results Of The Drug Screens:

Any Prior Research Experience: 
Appendix E

ANOVA Table for Threshold Time

\begin{tabular}{llll}
\hline Effects & $\underline{\mathrm{df}}$ & $\underline{\mathrm{F}}$ & $\underline{\mathrm{p}}$ \\
\hline $\mathrm{F} \times \mathrm{P} \times \mathrm{G}$ & 1 & .632 & .43 \\
$\mathrm{~F} \times \mathrm{P}$ & 1 & .028 & .87 \\
FXG & 1 & .264 & .61 \\
$\mathrm{P} \times \mathrm{G}$ & 1 & .856 & .36 \\
$\mathrm{~F}$ & 1 & .028 & .87 \\
$\mathrm{P}$ & 1 & 20.19 & .00 \\
$\mathrm{G}$ & 1 & 2.993 & .09 \\
\hline
\end{tabular}

Note. $F=$ Fear $P=$ Pain $; G=$ Gender 
Appendix F

ANOVA Table for Tolerance Time

\begin{tabular}{llll}
\hline Effects & $\underline{\mathrm{df}}$ & $\underline{\mathrm{F}}$ & $\underline{\mathrm{p}}$ \\
\hline $\mathrm{F} \times \mathrm{P} \times \mathrm{G}$ & 1 & .004 & .95 \\
$\mathrm{~F} \times \mathrm{P}$ & 1 & .224 & .64 \\
$\mathrm{~F} \times \mathrm{G}$ & 1 & .037 & .85 \\
$\mathrm{P} \times \mathrm{G}$ & 1 & .001 & .98 \\
$\mathrm{~F}$ & 1 & 1.575 & .22 \\
$\mathrm{P}$ & 1 & 43.96 & .00 \\
$\mathrm{G}$ & 1 & 4.721 & .036 \\
\hline
\end{tabular}

Note. $F=$ Fear $P=$ Pain $; G=$ Gender 
Appendix G

ANOVA Table for Verbal Reports of Fear

\begin{tabular}{llll}
\hline$\underline{\text { Effects }}$ & $\underline{\mathrm{df}}$ & $\underline{\mathrm{F}}$ & $\underline{\mathrm{p}}$ \\
\hline $\mathrm{FXPXG}$ & 1 & .506 & .48 \\
$\mathrm{FXP}$ & 1 & 1.36 & .25 \\
$\mathrm{FXG}$ & 1 & .606 & .44 \\
$\mathrm{PXG}$ & 1 & .184 & .67 \\
$\mathrm{~F}$ & 1 & 2.45 & .13 \\
$\mathrm{P}$ & 1 & 23.30 & .00 \\
$\mathrm{G}$ & 1 & 2.419 & .13 \\
\hline
\end{tabular}

Note. $\mathrm{F}=$ Fear; $\mathrm{P}=$ Pain; $\mathrm{G}=$ Gender 
Appendix $\mathrm{H}$

ANOVA Table for Verbal Reports of Pain

\begin{tabular}{llll}
\hline$\underline{\text { Effects }}$ & $\underline{\mathrm{df}}$ & $\underline{\mathrm{F}}$ & $\underline{\mathrm{p}}$ \\
\hline $\mathrm{F} \times \mathrm{P} \times \mathrm{G}$ & .027 & .87 \\
$\mathrm{FXP}$ & .238 & .63 \\
$\mathrm{FXG}$ & 1.756 & .19 \\
$\mathrm{PXG}$ & 1.758 & .19 \\
$\mathrm{~F}$ & 2.501 & .12 \\
$\mathrm{P}$ & 33.06 & .00 \\
$\mathrm{G}$ & 3.445 & .07 \\
\hline
\end{tabular}

Note. $F=$ Fear $; P=$ Pain; $G=$ Gender 
Appendix I

ANOVA Table for Heart Rate

\begin{tabular}{|c|c|c|c|}
\hline Effects & $\underline{\mathrm{df}}$ & $\underline{F}$ & $\underline{p}$ \\
\hline$F \times P \times G$ & & 2.078 & .16 \\
\hline$F \times P$ & & 7.294 & .01 \\
\hline$F \times G$ & & .943 & .34 \\
\hline$P \times G$ & & 1.089 & .30 \\
\hline $\mathrm{F}$ & & 1.508 & .23 \\
\hline $\mathrm{P}$ & & 5.167 & .03 \\
\hline$G$ & & .063 & .80 \\
\hline
\end{tabular}

Note. $\mathrm{F}=$ Fear; $\mathrm{P}=$ Pain; $\mathrm{G}=$ Gender 
Appendix $J$

ANOVA Table for Threshold Time (Between Subjects)

\begin{tabular}{llll}
\hline Effects & $\underline{\mathrm{df}}$ & $\underline{\mathrm{F}}$ & $\underline{\mathrm{p}}$ \\
\hline $\mathrm{F} \times \mathrm{P} \times \mathrm{G}$ & 1 & .216 & .65 \\
$\mathrm{~F} \times \mathrm{P}$ & 1 & .779 & .38 \\
$\mathrm{FXG}$ & 1 & 1.131 & .30 \\
$\mathrm{P} \times \mathrm{G}$ & 1 & 1.89 & .18 \\
$\mathrm{~F}$ & 1 & .002 & .96 \\
$\mathrm{P}$ & 1 & 2.842 & .10 \\
$\mathrm{G}$ & 1 & .270 & .61 \\
\hline
\end{tabular}

Note. $F=$ Fear; $P=$ Pain; $G=$ Gender 
Appendix K

ANOVA Table for Tolerance Time (Between Subjects)

\begin{tabular}{lccc}
\hline$\underline{\text { Effects }}$ & $\underline{\mathrm{df}}$ & $\underline{\mathrm{F}}$ & $\underline{\mathrm{p}}$ \\
\hline $\mathrm{F} \times \mathrm{P} \times \mathrm{G}$ & 1 & .271 & .61 \\
$\mathrm{FXP}$ & 1 & .08 & .78 \\
$\mathrm{FXG}$ & 1 & .72 & .40 \\
$\mathrm{PXG}$ & 1 & 8.471 & .01 \\
$\mathrm{~F}$ & 1 & .146 & .71 \\
$\mathrm{P}$ & 1 & 14.355 & .00 \\
$\mathrm{G}$ & 1 & 13.641 & .00 \\
\hline
\end{tabular}

Note. $F=$ Fear $P=$ Pain; $G=$ Gender 
Appendix L

ANOVA Table for Verbal Reports of Fear (Between Subjects)

\begin{tabular}{lccc}
\hline$\underline{\text { Effects }}$ & $\underline{\mathrm{df}}$ & $\underline{\mathrm{F}}$ & $\underline{\mathrm{p}}$ \\
\hline $\mathrm{FXPXG}$ & 1 & .149 & .70 \\
$\mathrm{FXP}$ & 1 & .042 & .84 \\
$\mathrm{FXG}$ & 1 & .292 & .59 \\
$\mathrm{PXG}$ & 1 & 3.298 & .08 \\
$\mathrm{~F}$ & 1 & .00 & .99 \\
$\mathrm{P}$ & 1 & 14.332 & .01 \\
$\mathrm{G}$ & 1 & 3.163 & .09 \\
\hline
\end{tabular}

Note. $F=$ Fear; $P=$ Pain; $G=$ Gender 


\section{Appendix M}

ANOVA Table for Verbal Reports of Pain (Between Subjects)

\begin{tabular}{lcll}
\hline Effects & $\underline{\mathrm{df}}$ & $\underline{\mathrm{F}}$ & $\underline{\mathrm{p}}$ \\
\hline $\mathrm{F} \times \mathrm{P} \times \mathrm{G}$ & 1 & .287 & .60 \\
FXP & 1 & .168 & .69 \\
$\mathrm{FXG}$ & 1 & .937 & .34 \\
$\mathrm{P} \times \mathrm{G}$ & 1 & 2.911 & .10 \\
$\mathrm{~F}$ & 1 & .104 & .75 \\
$\mathrm{P}$ & 1 & 2.866 & .10 \\
$\mathrm{G}$ & 1 & 3.312 & .08 \\
\hline
\end{tabular}

Note. $F=$ Fear $; P=$ Pain; $G=$ Gender 
Appendix N

ANOVA Table for Heart Rate (Between Subjects)

\begin{tabular}{lccc}
\hline$\underline{\text { Effects }}$ & $\underline{\mathrm{df}}$ & $\underline{\mathrm{F}}$ & $\underline{\mathrm{p}}$ \\
\hline $\mathrm{FXPXG}$ & 1 & 3.852 & .06 \\
$\mathrm{FXP}$ & 1 & .384 & .54 \\
$\mathrm{FXG}$ & 1 & .702 & .41 \\
$\mathrm{PXG}$ & 1 & 1.517 & .23 \\
$\mathrm{~F}$ & 1 & .736 & .40 \\
$\mathrm{P}$ & 1 & 4.074 & .05 \\
$\mathrm{G}$ & 1 & .39 & .54 \\
\hline
\end{tabular}

Note. $F=$ Fear $P=$ Pain $; G=$ Gender 
Table 1

$\underline{\text { Pain locations and total number and percent of participants with that chronic pain site }}$

$\begin{array}{ll}\text { Pain Location } & \\ \text { Lower back } & (\underline{\mathrm{n}}=26 ; 65 \%) \\ \text { Neck } & (\underline{\mathrm{n}}=3 ; 7.5 \%) \\ \text { Hip } & (\underline{\mathrm{n}}=3 ; 7.5 \%) \\ \text { Shoulder } & (\underline{\mathrm{n}}=2 ; 5 \%) \\ \text { Head } & (\underline{\mathrm{n}}=2 ; 5 \%) \\ \text { Groin } & (\underline{\mathrm{n}}=2 ; 5 \%) \\ \text { Knee } & (\underline{\mathrm{n}}=1 ; 2.5 \%) \\ \text { Testicles } & (\underline{\mathrm{n}}=1 ; 2.5 \%)\end{array}$

Note. $\underline{n}=40$. 
Table 2

Medications used by participants as part of their treatment at the pain treatment center

Medication Type

Antihistamine

Hormone Replacement

Antidepressant

Hypertension

Ulcer Medication

Renal Medication

Anxiolytic

Analgesic

Narcotic

Anticonvulsant/Seizure

Anti-Inflammatory

Cholesterol Medication

Thyroid Medication

Diuretic

Anticoagulant

Muscle Relaxant

Dietary Supplement

Antibiotic
Frequency

4

8

26

10

5

1

9

9

26

17

12

4

1

1

1

12

1

2
Percent

10

20

65

25

12.5

2.5

22.5

22.5

65

42.5

30

10

2.5

2.5

2.5

30

2.5

5 
Table 3

\section{Exclusion Criteria}

1. Heart disease

2. Peripheral neuropathy or polyneuropathy in the upper extremities

3. Reflex sympathetic dystrophy (RSD) in the upper extremities

4. Missing middle or ring finger on either hand

5. Use of morphine pump

6. Under age 18 years

7. Over age 65 years

8. Open wound on either middle or ring fingers 
Table 4

\section{Participant Demographics}

$\underline{\text { Variable }}$

Gender

Male

Female

Mean age

Ethinicity

Caucasian

African-American

Mean pain chronicity (months) 103.5

Marital status

Married

29

Separated or divorced 5

Single

Widowed

Live-in partner

20

20

43.3

38 $\underline{\text { Total Number/Mean }}$

|95\%|

$|5 \%|$

88.9

|72.5\%|

|12.5\%|

|15\%|

|2.5\%|

|2.5\% | 
Table 5

Mean and standard deviation values for all three modes of responding by condition

Mode of Responding

$\underline{\text { Condition }}$

High Fear/High Pain High Fear/Low Pain Low Fear/High Pain Low Fear/Low Pain

$\underline{\text { Overt Behavior }}$

Tolerance

$149.12(121.62)$

$239.23(93.07)$

$155.85(121.33)$

$253.53(80.08)$

$\underline{\text { Verbal Report }}$

Threshold

$26.20(22.36)$

$74.30(90.64)$

26.15 (29.98)

$72.50(76.80)$

Fear

$24.91(26.53)$

$12.04(18.84)$

$19.84(22.70)$

$10.46(16.70)$

Pain

$54.46(27.16)$

$37.90(27.93)$

52.31 (26.59)

$34.16(25.65)$

$\underline{\text { Physiological }}$

Heart Rate $\quad .75(4.56)$

$-1.26(3.97)$

$-0.63(3.97)$

$-0.67(3.43)$

$\underline{\text { Note. }} \underline{n}=40$. For the fear, pain, and heart rate measures, change scores were utilized. See Data Processing and Analysis of Results sections for definition of change scores. 
Table 6

Mean scores and standard deviations (SD) for the four self-report measures used in the present study and

Zvolensky, Goodie, McNeil, Sperry, and Sorrell (2000).

Present Study

Mean and (SD)

Measure Scale

FPQ-III

Severe

Minor

Medical

Total

PASS

Cognitive

Escape/Avoidance

Fearful Appraisal

Physiological

Total

ASI

$$
\text { Physical }
$$

Psychological

Social Concerns

Total

BDI-II
$38.78 \quad(7.31)$

$21.08 \quad(7.70)$

$26.55 \quad(9.29)$

$86.40 \quad(21.03)$

$32.00 \quad(11.83)$

$28.63 \quad(9.41)$

$23.15 \quad(10.22)$

$23.48 \quad(11.01)$

$15.30 \quad(8.93)$

$7.60 \quad(6.17)$

$5.60 \quad(1.58)$

$28.50 \quad$ (14.32)

$22.60 \quad(11.55)$
107.25 (37.90)
Zvolensky et al. (2000)

Mean and (SD)

$32.1 \quad(11.7)$

$19.3 \quad(10.2)$

$23.0 \quad(9.5)$

$74.5 \quad(26.6)$

$27.3 \quad(12.0)$

$26.1 \quad$ (10.6)

$19.5 \quad(10.2)$

$19.5 \quad$ (11.4)

$92.4 \quad(38.6)$

$10.8 \quad(9.2)$

$4.7 \quad(5.2)$

$4.8 \quad(2.0)$

$20.3 \quad(14.5)$

$20.0 \quad$ (13.5)

$\underline{\text { Note. }} \underline{\mathrm{n}}=40$ in present study and $\underline{\mathrm{n}}=68$ in Zvolensky et al. (in press). 


\section{Figure Captions}

Figure 1. Number Rating Scales (NRS) used by participants for verbal reports of fear and pain.

Figure 2. "Painful" and "Stop Stimulation" signs used by participants to indicate when the pressure stimulation became painful (i.e., threshold) and/or to stop the condition (i.e., tolerance), respectively.

Figure 3. Illustration of procedural flow for present study.

Figure 4. Mean threshold times (s) for all participants in each condition.

Figure 5 . Mean tolerance times for participants across each condition.

Figure 6. Mean tolerance times for male and female participants across each condition.

Figure 7. Mean fear change ratings for all participants in each condition.

Figure 8. Mean pain change ratings for all participants in each condition.

Figure 9. Mean change scores for heart rate across the four conditions. 


\section{Fear Rating Scale}

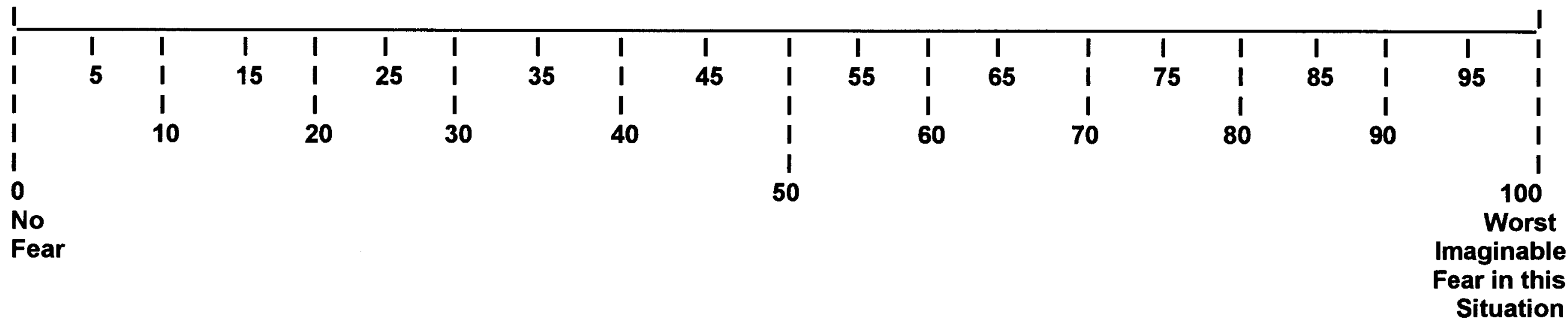

Pain Rating Scale

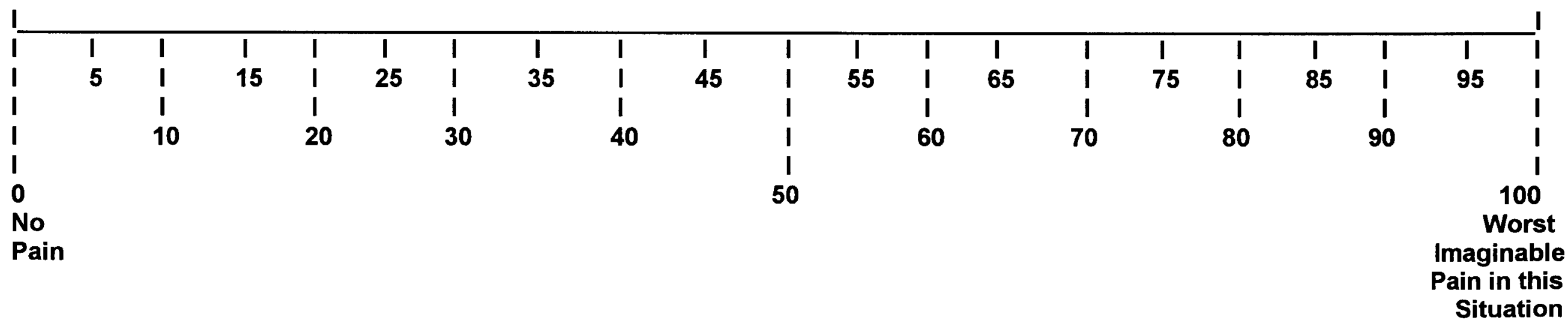




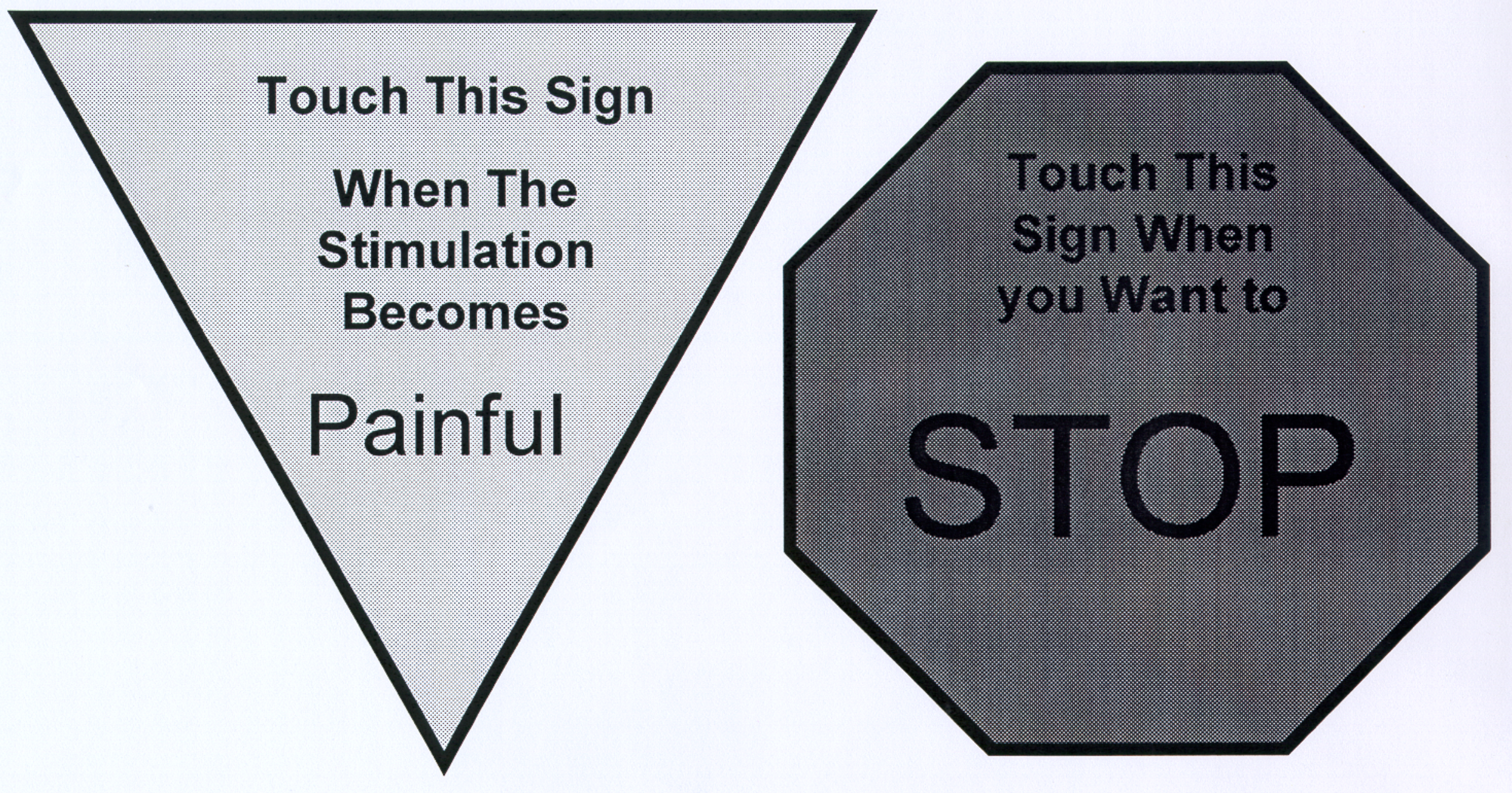




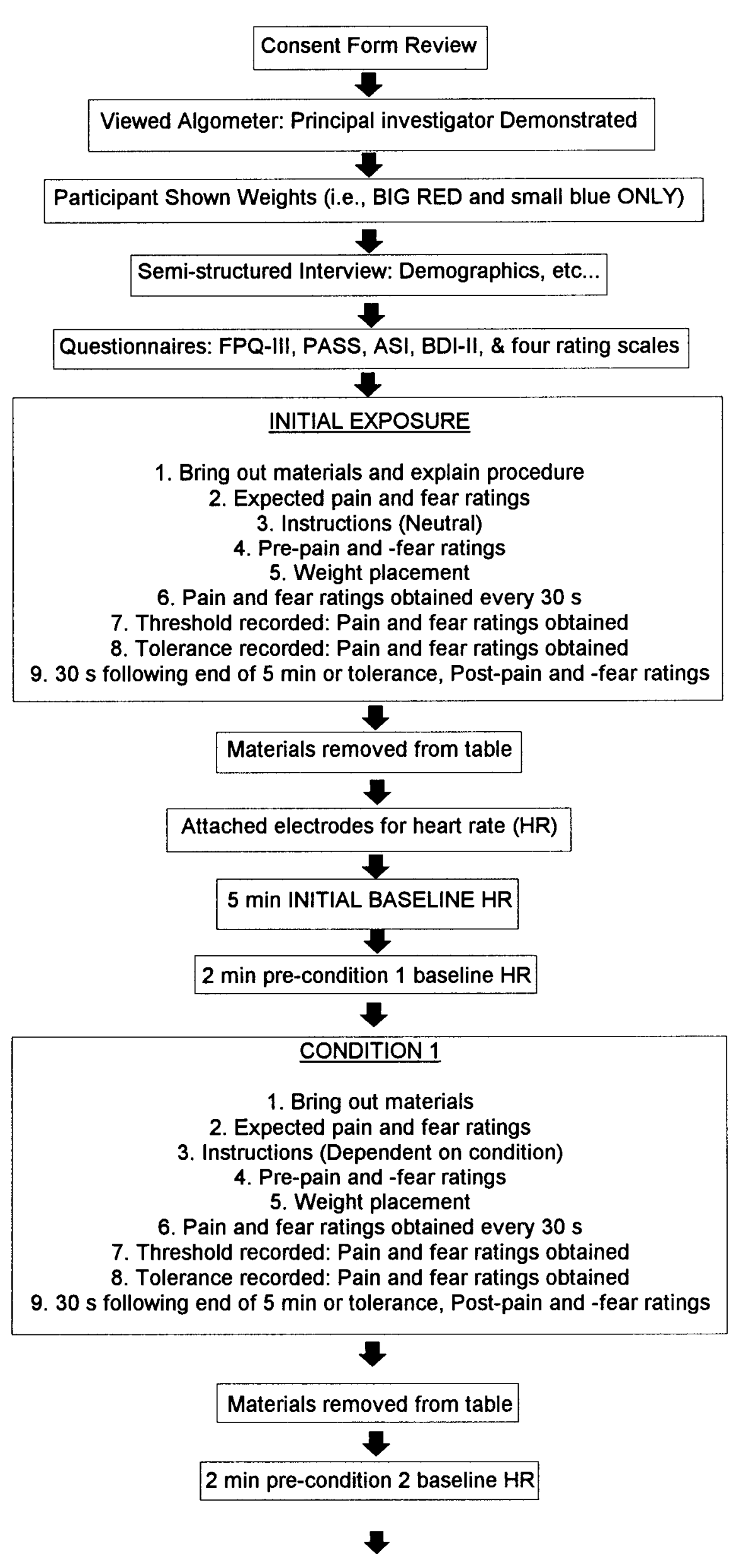

(Figure 3 continues on next page) 


\section{CONDITION 2}

1. Bring out materials

2. Expected pain and fear ratings

3. Instructions (Dependent on condition)

4. Pre-pain and -fear ratings

5. Weight placement

6. Pain and fear ratings obtained every $30 \mathrm{~s}$

7. Threshold recorded: Pain and fear ratings obtained

8. Tolerance recorded: Pain and fear ratings obtained

9. $30 \mathrm{~s}$ following end of $5 \mathrm{~min}$ or tolerance, Post-pain and -fear ratings

Materials removed from table

2 min pre-condition 3 baseline HR

\section{CONDITION 3}

1. Bring out materials

2. Expected pain and fear ratings

3. Instructions (Dependent on condition)

4. Pre-pain and -fear ratings

5. Weight placement

6. Pain and fear ratings obtained every $30 \mathrm{~s}$

7. Threshold recorded: Pain and fear ratings obtained

8. Tolerance recorded: Pain and fear ratings obtained

9. $30 \mathrm{~s}$ following end of $5 \mathrm{~min}$ or tolerance, Post-pain and -fear ratings

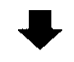

Materials removed from table

2 min pre-condition 4 baseline HR

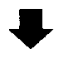

\section{CONDITION 4}

1. Bring out materials

2. Expected pain and fear ratings

3. Instructions (Dependent on condition)

4. Pre-pain and -fear ratings

5. Weight placement

6. Pain and fear ratings obtained every $30 \mathrm{~s}$

7. Threshold recorded: Pain and fear ratings obtained

8. Tolerance recorded: Pain and fear ratings obtained

9. $30 \mathrm{~s}$ following end of $5 \mathrm{~min}$ or tolerance, Post-pain and -fear ratings

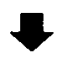

Materials removed from table

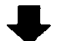

5 min INITIAL BASELINE HR

Participant debriefed 


\section{Mean Pain Threshold Time}

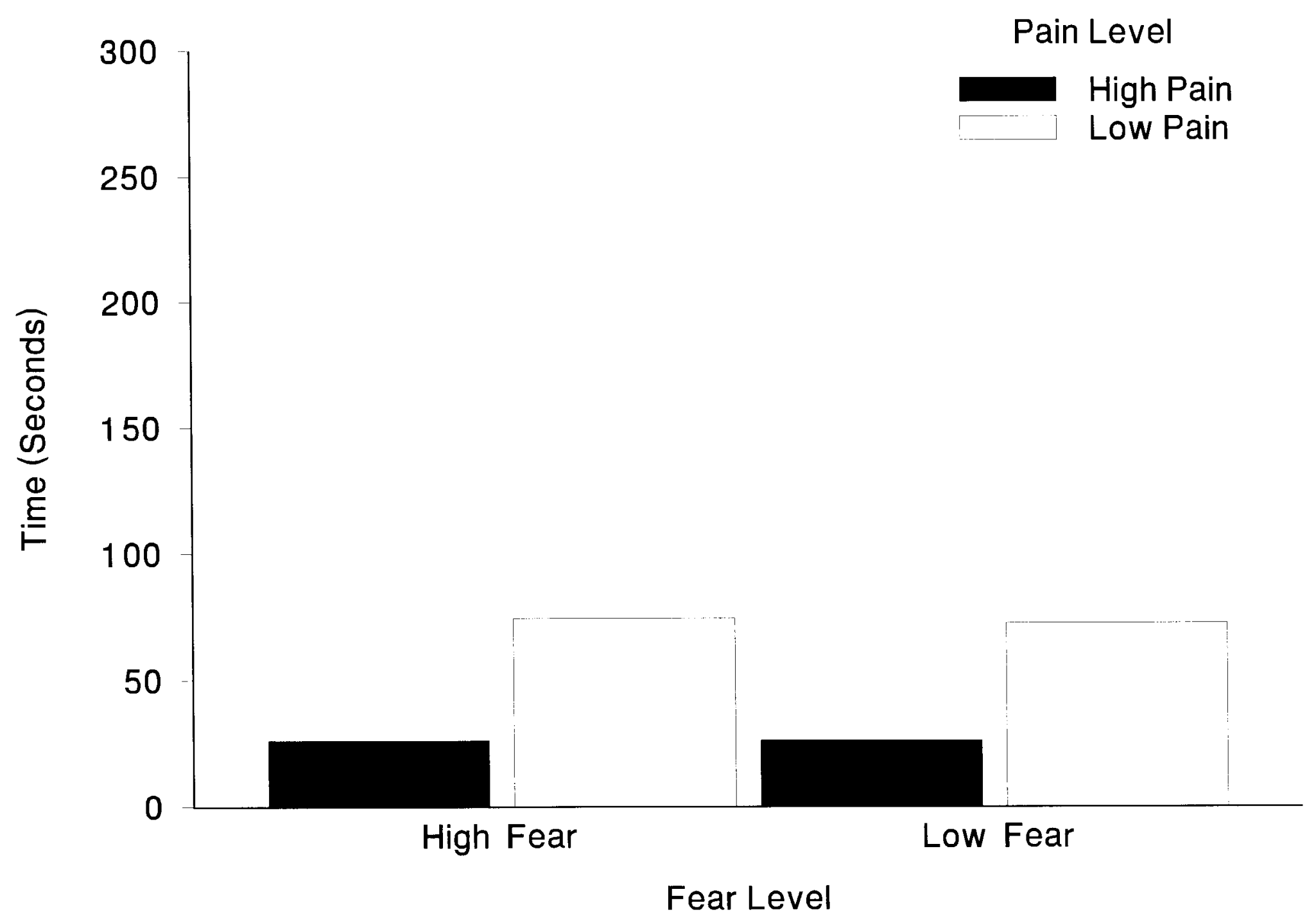




\section{Mean Pain Tolerance Time}

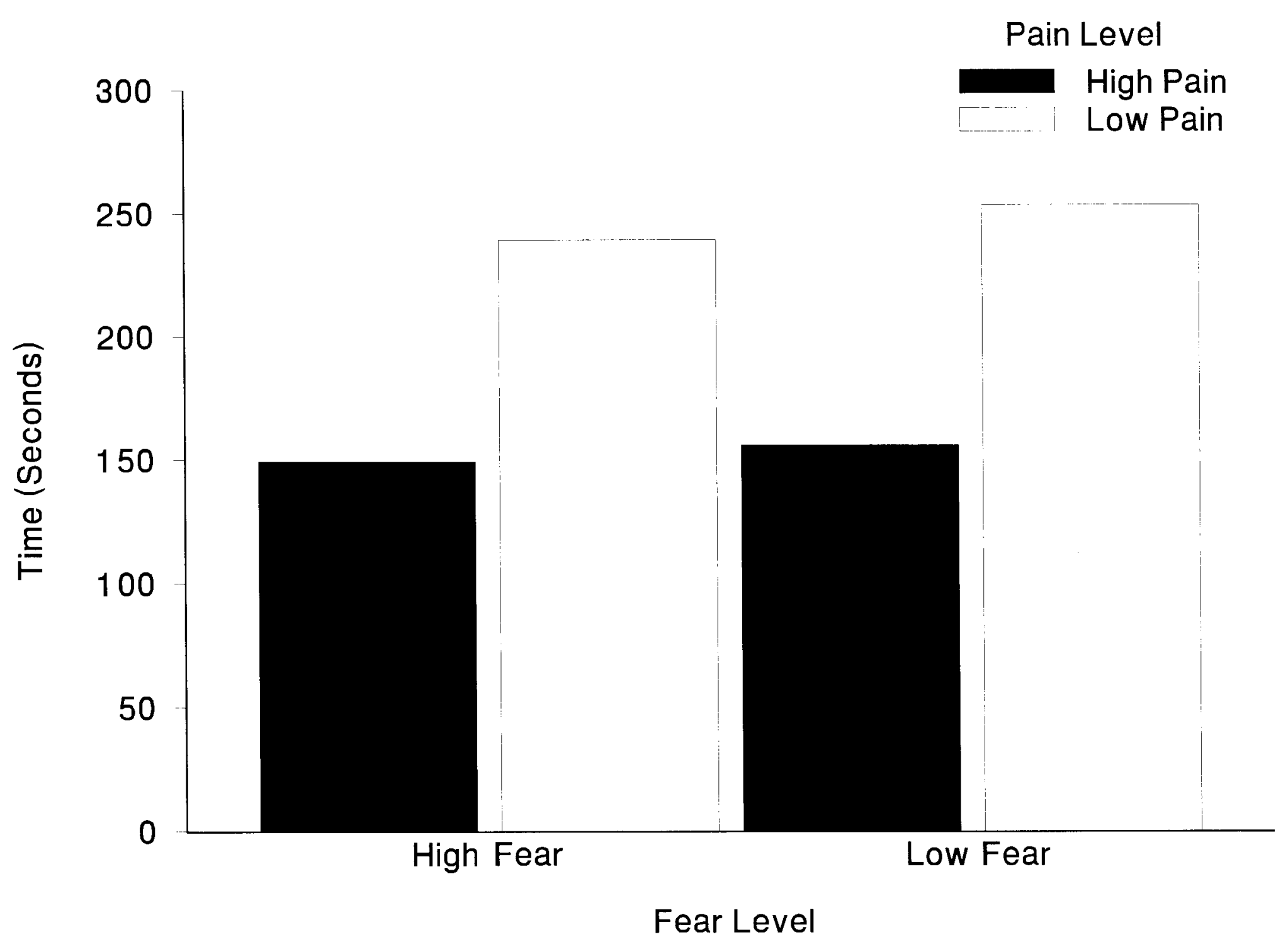




\section{Male and Female Mean Pain Tolerance Times}

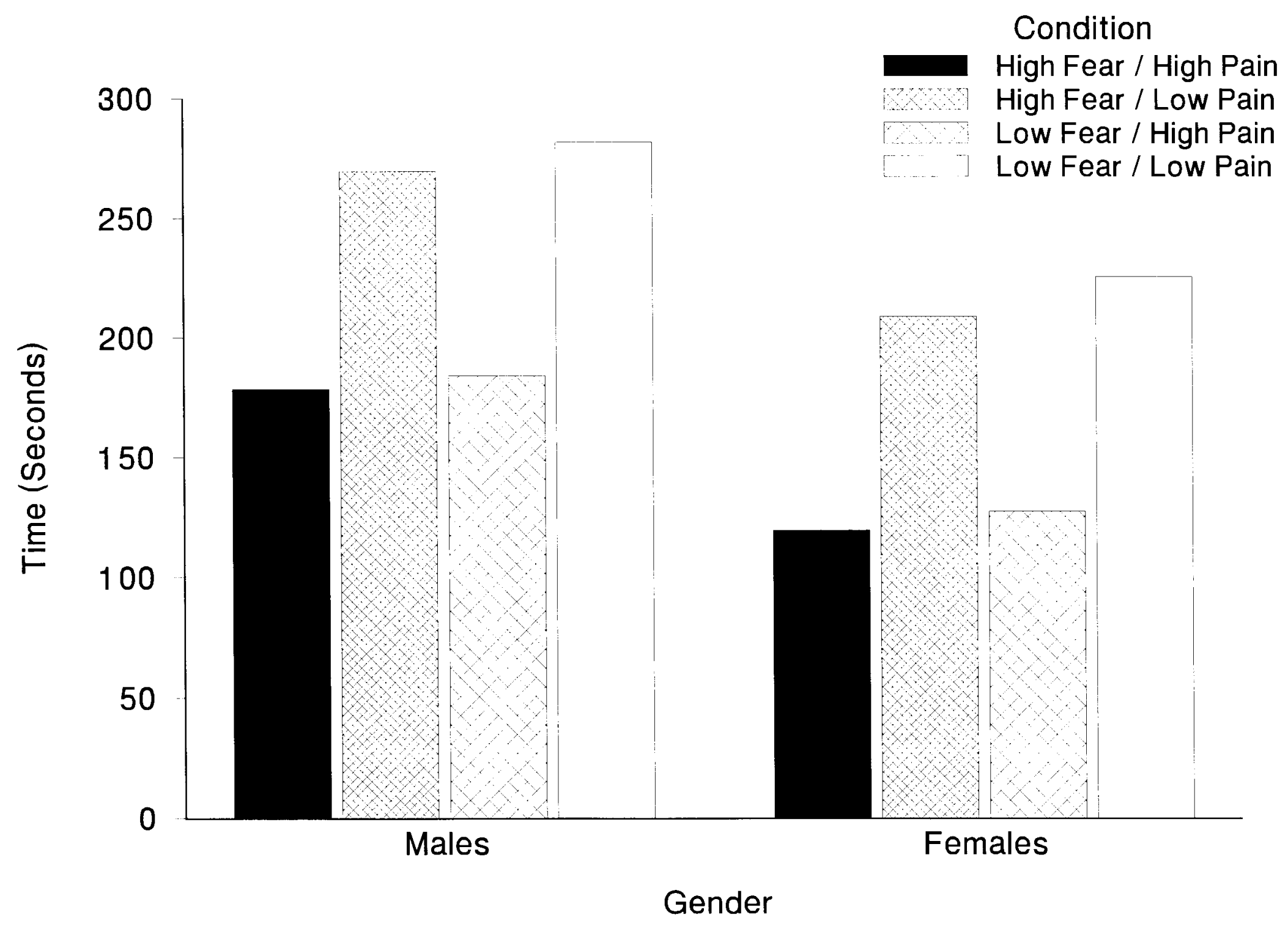




\section{Mean Fear Change Ratings}

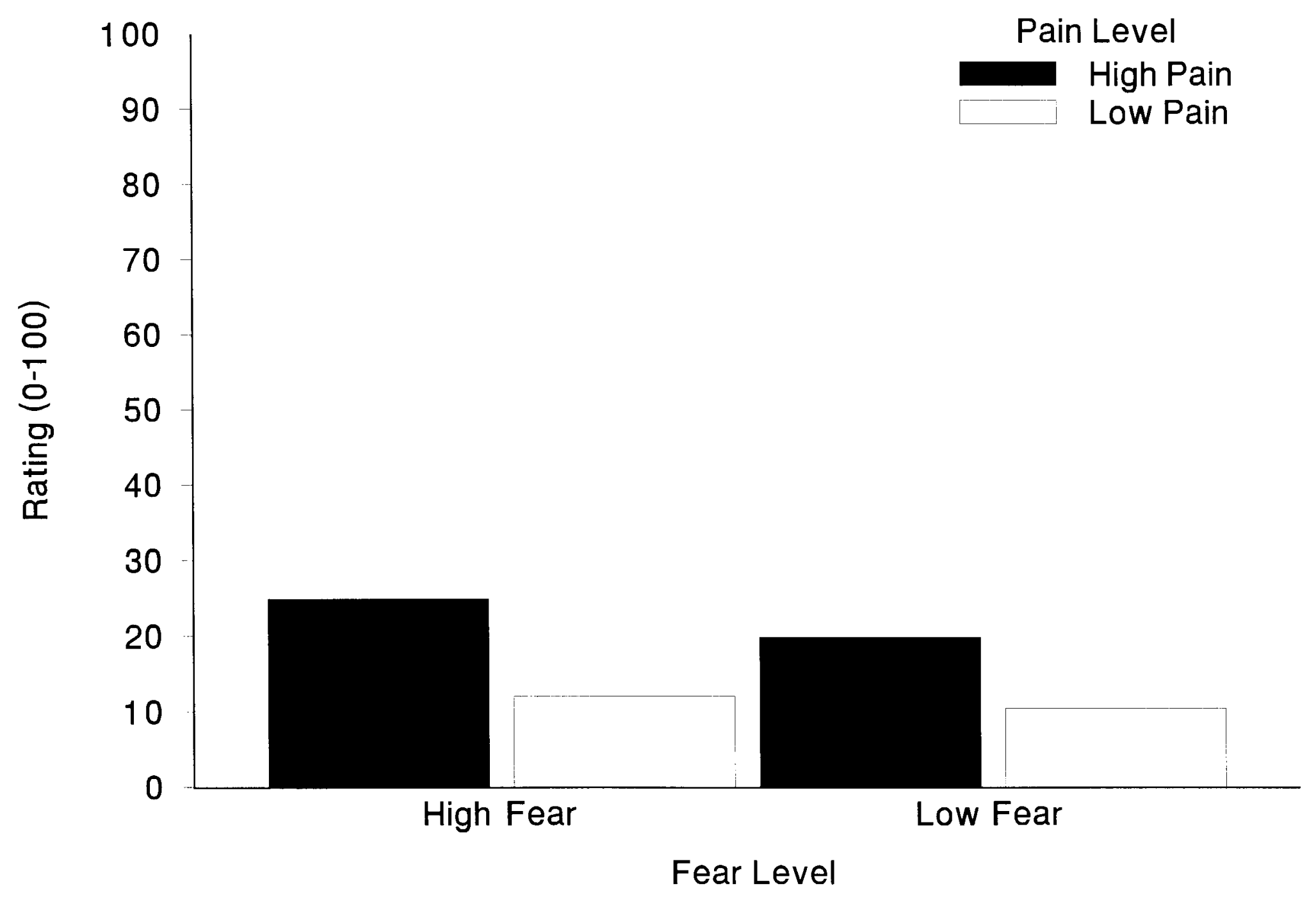




\section{Mean Pain Change Ratings}

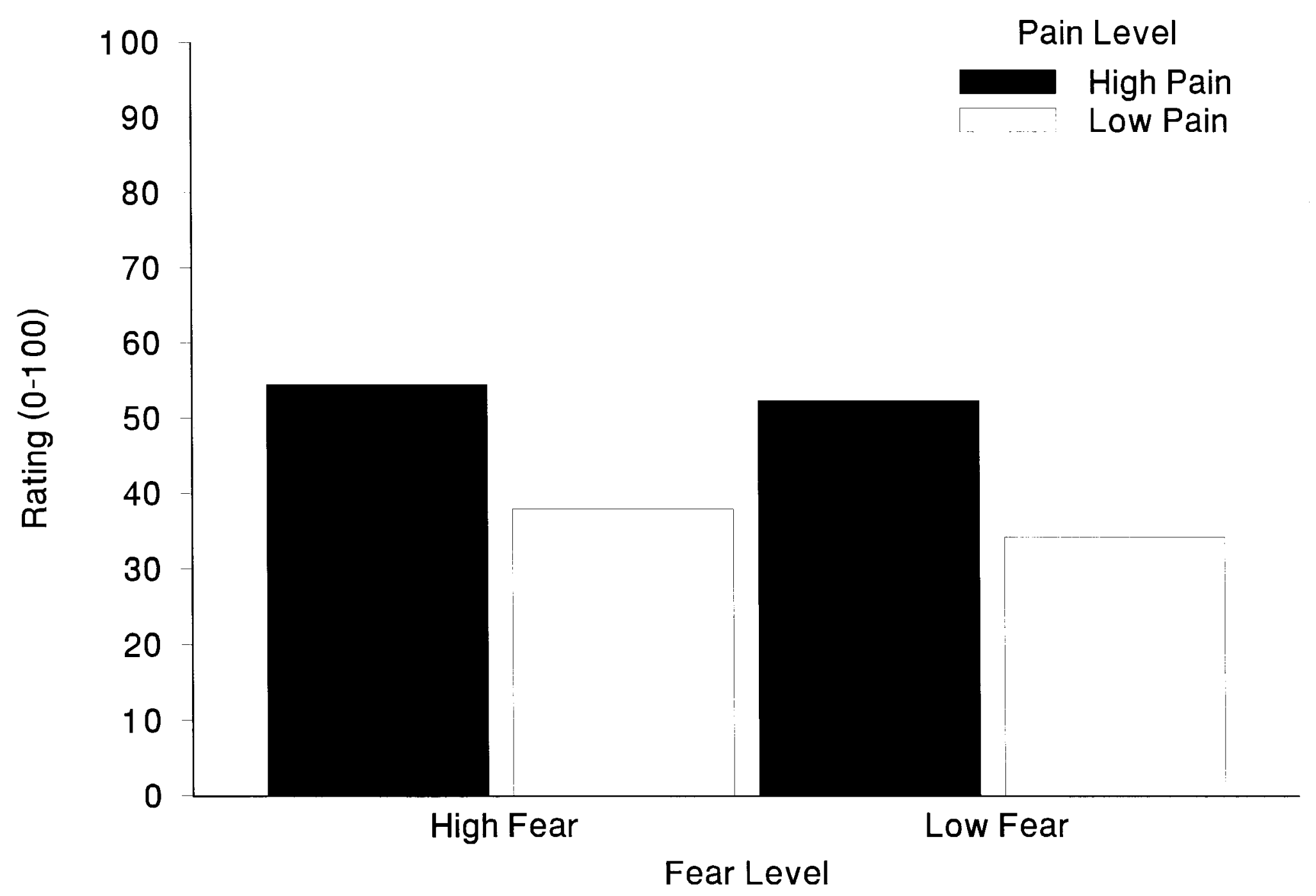




\section{Heart Rate Change Scores}

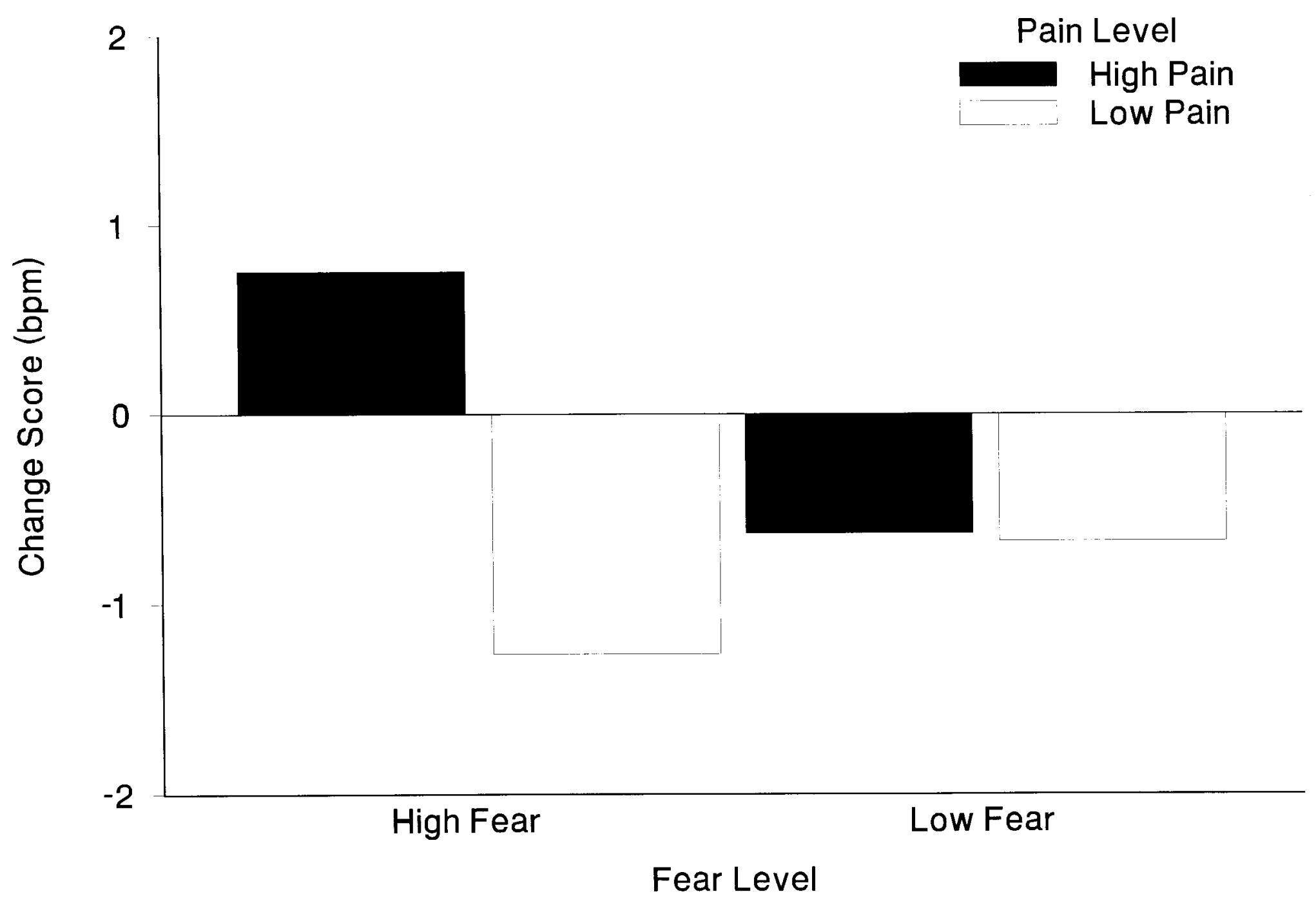

